\title{
Glycerol Nucleoside Triphosphates: Synthesis and Polymerase Substrate Activities
}

\author{
Allen T. Horhota ${ }^{1}$, Jack W. Szostak ${ }^{2}$, and Larry W. McLaughlin ${ }^{1}$ \\ ${ }^{I}$ Department of Chemistry, Boston College, Chestnut Hill, MA 0246 \\ ${ }^{2}$ Howard Hughes Medical Institute, and Department of Molecular Biology, \\ Massachusetts General Hospital, Boston, 02114
}

\section{Supporting Information}


Table of Contents:

1) General Experimental Procedures 3

2) General Phosphorylation and Purification Procedures 3

3) (S)-gTTP 4

4) (S)-gGTP 6

5) $(\mathrm{S})$-gCTP

6) (S)-gATP 10

7) Polymerase Experiments 11

8) NMR Spectra 13 


\section{1) General Experimental}

Reagents were purchased from Sigma, Aldrich, Acros, MP, and Lancaster. Flash Chromatography was performed using Sorbent Technologies (Atlanta, GA) $60 \AA$ Silica Gel with TLC monitoring on EMD (Gibbstown, NJ) Silica Gel 60 F254 plates. UV spectra were aquired using a Beckman (Fullerton, CA) DU650 spectrophotometer. High and low resolution mass spectroscopy was performed by Boston College mass spectroscopy facility. NMR spectra were gathered on either a Varian Gemini 400 or Unity $300 \mathrm{MHz}$ with TMS as interal $\mathrm{H}^{1}$ standard, solvent peaks for $\mathrm{C}^{13}$, and external phosphoric acid for $\mathrm{P}^{31}$ spectra. HPLC purification was performed on a Waters (Milford, MA) Delta 600 system with a 2487 dual wavelength detector. DNA oligomers were prepared using an Applied Biosystems 394 DNA/RNA synthesizer using standard solid phase phosphoramidite techniques and reagents purchased from Glenn Research (Sterling, VA). RNA oligomers were purchased from Dharmacon (Lafayette, CO). PAG Electrophoresis was performed using Bio-Rad (Hercules, CA) Sequigen-GT or Hoefer Scientific (San Fransisco, CA) apparatus. Gel imaging was performed on a Bio-Rad FXpro Molecular Imager using Kodak-K radioisotope screens.
Abbreviations: $\mathrm{DCM}=$ Dichloromethane, $\mathrm{MeOH}=$ Methanol, TEA $=$ Triethylamine, $\mathrm{DCAA}=$ Dichloroacetic Acid, PNK = Polynucleotide Kinase, DMF =
Dimethylformamide, TEAB $=$ Triethylammonium Bicarbonate, TEAA $=$
Triethylammonium acetate, $\mathrm{gNTPs}=$ glycerol nucleoside triphosphates, $\mathrm{DMTr}=$ dimethoxytrityl

\section{2) General Phosphorylation and Purification Procedure}

Triphosphate syntheis was carried out according to method developed by Eckstein et. al. All solvents were freshly distilled. Compounds were dried using two coevaporations with freshly distilled pyridine followed by remaining $2 \mathrm{hr}$ under vacuum over $\mathrm{P}_{2} \mathrm{O}_{5}$ after which time an argon atmosphere was introduced and maintained throughout the reaction. Compounds were dissolved in pyridine and dioxane $(A, T$, and C) or pyridine and DMF (G) then treated with 1 equivalent of 2-chloro-4H-1,3,2dioxaphosphorin-4-one (1M in dioxane) and allowed to stir at ambient temperature for 15 minutes. 1.5 eq. of tributylammonium pyrophosphate in DMF and tributylamine were added and allowed to stir for $15 \mathrm{~min} .1 \% \mathrm{I}_{2}$ in pyridine/ water $98 / 2$ was added and allowed to react for $15 \mathrm{~min}$. Solvents were removed and two diethyl ether washes were performed to remove excess iodine. Water layers were then treated with concentrated $\mathrm{NH}_{4} \mathrm{OH}$ for 8 hours at $55^{\circ} \mathrm{C}$ for $\mathrm{A}, \mathrm{C}$, and $\mathrm{G}$, and $1 \mathrm{~h}$ at ambient temperature for $\mathrm{T}$ followed by ammonia removal under vacuum.

Ion exchange chromatography was performed using a Mono Q HR 10/10 column eluting with a linear gradient from 0 to $1 \mathrm{M} \mathrm{TEAB} \mathrm{pH} \mathrm{7.5.} \mathrm{Reverse} \mathrm{phase}$ chromatography was performed using a $250 \times 10 \mathrm{~mm}$ divinyl benzene column eluting with 100\% 0.1 M TEAA pH 7.0 to 50:50 methanol: TEAA. Cation exchange was performed using Dowex 50WX8-100 resin in the $\mathrm{Na}^{+}$form. ${ }^{31} \mathrm{P}$ NMR was carried out in $\mathrm{D}_{2} \mathrm{O}$. 


\section{3) (S)-gTTP Synthesis}

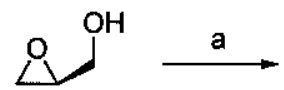

R-(+)-Glycidol<smiles>Cc1cn(C[C@@H](O)CO)c(=O)[nH]c1=O</smiles>

(1)<smiles>Cc1cn(C[C@H](O)CO[Na])c(=O)[nH]c1=O</smiles>

(2)<smiles>CCCC</smiles>

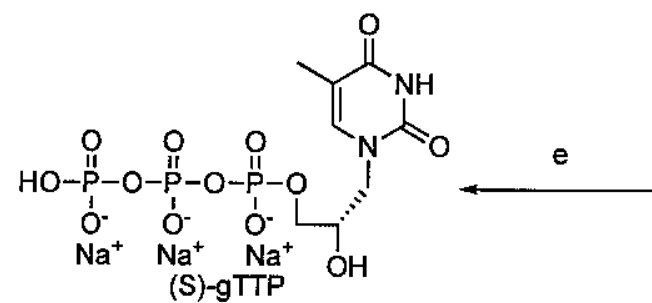

(5)

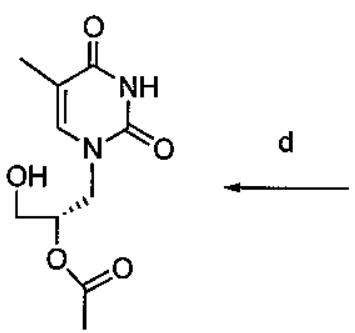

(4)<smiles>CC(=O)OC[C@H](Cn1cc(C)c(=O)[nH]c1=O)OC(=O)O</smiles>

(3)

(a) Thymine/ 0.1 eq. $\mathrm{K}_{2} \mathrm{CO}_{3} / \mathrm{DMF} / 85^{\circ} \mathrm{C} / 12 \mathrm{~h}$; (b) 1.1 eq. DMTr-Cl/ pyridine/ $8 \mathrm{~h} / \mathrm{rt}$; (c) 4 eq. $\mathrm{Ac} 2 \mathrm{O} /$ pyridine $/ 3$ $\mathrm{h} / \mathrm{rt}$; (d) Dichloroacetic acid/ DCM/ $20 \mathrm{~min} / \mathrm{it}$ (e) i.) 1 eq. 2-chloro-4H-1,3,2-benzodioxaphosphorin-4-one/ dioxane/ pryridine/ $15 \mathrm{~min} / \mathrm{rt}$;ii.) Tributylammonium pyrophosphate/ DMF/ tributylamine/ $15 \mathrm{~min} / \mathrm{rt} ; \mathrm{iii}$ ) $1 \% \mathrm{I}_{2}$ in $98 / 2$ pyridine/ $\mathrm{H}_{2} \mathrm{O} / 15 \mathrm{~min} / \mathrm{rt} ; i \mathrm{v}$.) $\mathrm{NH}_{4} \mathrm{OH} / 1 \mathrm{~h} / \mathrm{r}$; v.) Dowex $50 \mathrm{WX} 8 \mathrm{Na}^{+}$

\section{Compound (1)}

Thymine was dissolved in DMF at $85^{\circ} \mathrm{C}$ and 0.2 eq. of $\mathrm{K}_{2} \mathrm{CO}_{3}$ were added followed by 1 eq. (R)-+-glycidol and stirred for 24 hours. Product eluted from silica gel in $7 \% \mathrm{MeOH}: \mathrm{DCM}$ at $45 \%$ yield as a white powder.

Rf: 0.3 (DCM: $\mathrm{MeOH} ; 90: 10, \mathrm{v} / \mathrm{v}$ )

${ }^{1} \mathrm{H}$ NMR (DMSO-d ${ }_{6}$ ) $\delta: 1.77(\mathrm{~d}, 3 \mathrm{H}, \mathrm{J}=0.8 \mathrm{~Hz}$ ), 3.31-3.41(m, 3H), $3.70(\mathrm{dd}, 1 \mathrm{H}, \mathrm{J}=3.2$ $\mathrm{Hz}), 3.91(\mathrm{dd}, 1 \mathrm{H}, \mathrm{J} 1=3 \mathrm{~Hz}, \mathrm{~J} 2=14 \mathrm{~Hz}), 4.71(\mathrm{t}, 1 \mathrm{H}, \mathrm{J}=6 \mathrm{~Hz}), 5.00(\mathrm{~d}, 1 \mathrm{H}, \mathrm{J}=5 \mathrm{~Hz}), 7.41(\mathrm{~d}$, $1 \mathrm{H}, \mathrm{J}=1.2 \mathrm{~Hz}$ ), 11.21(s, 1H). ${ }^{13} \mathrm{C}$ NMR $\left(\mathrm{DMSO}_{-} \mathrm{d}_{6}\right) \delta: 12.1,50.9,63.7,69.1,107.3$, $142.7,150.8,164.1$

LRMS (EI) m/z $222.6\left[\mathrm{M}+\mathrm{Na}^{+}\right.$; calcd for $\left.\mathrm{C}_{8} \mathrm{H}_{12} \mathrm{~N}_{2} \mathrm{O}_{4} \mathrm{Na}: 223.1\right]$

$\lambda_{\max }(\mathrm{MeOH}): 270 \mathrm{~nm}$

\section{Compound (2)}

Compound 1 and 1.2 eq. of DMTr-Cl were dissolved in pyridine and stirred for 8 $\mathrm{hr}$ at ambient temperature. Solvent was removed under vacuum followed by two coevaporations with toluene. Product eluted by flash chromatography in 98:2:0.01 DCM:MeOH:TEA in $83 \%$ yield as a white foam.

Rf: 0.3 (DCM: $\mathrm{MeOH} ; 95: 5, \mathrm{v} / \mathrm{v}$ )

${ }^{1} \mathrm{H}$ NMR (DMSO-d $\left.\mathrm{d}_{6}\right) \delta: 1.59(\mathrm{~s}, 3 \mathrm{H}), 2.80\left(\mathrm{dq}, 2 \mathrm{H}, \mathrm{J}_{1}=4 \mathrm{~Hz}, \mathrm{~J}_{2}=37 \mathrm{~Hz}\right), 3.35\left(\mathrm{q}, 1 \mathrm{H}, \mathrm{J}_{1}=5\right.$

$\left.\mathrm{Hz}, \mathrm{J}_{2}=9 \mathrm{~Hz}\right), 3.64(\mathrm{~s}, 6 \mathrm{H}), 3.79(\mathrm{~m}, 2 \mathrm{H}), 5.15(\mathrm{~d}, 1 \mathrm{H}, \mathrm{J}=6 \mathrm{~Hz}), 6.78-7.32(\mathrm{~m}, 14 \mathrm{H}$, aromatic), 11.10(s, 1H). ${ }^{13} \mathrm{C}$ NMR (DMSO-d 6 ) $\delta: 12.0,51.2,55.0,65.6,67.4,85.3$, $107.4,113.0,126.4,127.5,127.6,129.5,135.5,142.4,144.7,150.8,157.8,164.1$

LRMS (EI) $\mathrm{m} / \mathrm{z} 525.2\left[\mathrm{M}+\mathrm{Na}^{+}\right.$; calcd for $\left.\mathrm{C}_{29} \mathrm{H}_{30} \mathrm{~N}_{2} \mathrm{O}_{6} \mathrm{Na}: 525.2\right]$ 
$\lambda_{\max }(\mathrm{DCM}): 233,272 \mathrm{~nm}$

\section{Compound (3)}

Compound 2 was dissolved in pyridine and treated with $4 \mathrm{eq}$, of acetic anhydride for $2 \mathrm{~h}$ at ambient temperature. Solvent was removed and coevaporated twice with toluene and purified by flash chromatography eluting with 99:1:0.01 DCM:MeOH:TEA in $95 \%$ yield as a white foam.

Rf: 0.4 (DCM: $\mathrm{MeOH} ; 97: 3, \mathrm{v} / \mathrm{v})$

${ }^{1} \mathrm{H}$ NMR (DMSO-d $)$ ) $8: 1.59(\mathrm{~s}, 3 \mathrm{H}), 1.93(\mathrm{~s}, 3 \mathrm{H}), 2.94(\mathrm{dd}, 1 \mathrm{H}, \mathrm{J} 1=3 \mathrm{~Hz}, \mathrm{~J} 2=10 \mathrm{~Hz}$ ), $3.01(\mathrm{dd}, 1 \mathrm{H}, \mathrm{J} 1=4 \mathrm{~Hz}, \mathrm{~J} 2=10 \mathrm{~Hz}$ ), 3.64(s, $6 \mathrm{H}), 3.71(\mathrm{dd}, 1 \mathrm{H}, \mathrm{J} 1=8 \mathrm{~Hz}, \mathrm{~J} 2=14 \mathrm{~Hz}$ ), $3.83(\mathrm{dd}, 1 \mathrm{H}, \mathrm{J} 1=4 \mathrm{~Hz}, \mathrm{~J} 2=14 \mathrm{~Hz}), 5.12(\mathrm{~m}, 1 \mathrm{H}), 6.8-7.3(\mathrm{~m}, 14 \mathrm{H}$, aromatic), $11.15(\mathrm{~s}, 1 \mathrm{H})$.

${ }^{13} \mathrm{C}$ NMR (DMSO-d 6 ) $\delta: 12.5,21.1,48.6,55.4,62.3,70.6,86.5,110.3,113.3,127.0$, $127.94,129.9,135.4,140.8,144.4,151.0,158.6,164.2,169.8$

LRMS (EI) m/z $567.2\left[\mathrm{M}+\mathrm{Na}^{+}\right.$; calcd for $\left.\mathrm{C}_{31} \mathrm{H}_{32} \mathrm{~N}_{2} \mathrm{O}_{7} \mathrm{Na}: 567.2\right]$

$\lambda_{\max }:$ DCM 237, $270 \mathrm{~nm}$

\section{Compound (4)}

Compound 3 was dissolved in dry DCM and treated with 3\% DCAA in DCM for 15 min until starting material disappeared by TLC. Solution was loaded directly over silica, washed with 3 column volumes DCM and eluted in 97:3 DCM:MeOH in 93\% yield as a white powder.

Rf: 0.3 (DCM: $\mathrm{MeOH} ; 95: 5, \mathrm{v} / \mathrm{v})$

${ }^{1} \mathrm{H}_{\mathrm{NMR}}\left(\mathrm{DMSO}-\mathrm{d}_{6}\right) \delta: 1.74(\mathrm{~s}, 3 \mathrm{H}), 1.95(\mathrm{~s}, 3 \mathrm{H}), 3.50(\mathrm{~m}, 2 \mathrm{H}), 3.65(\mathrm{dd}, 1 \mathrm{H}, \mathrm{J} 1=9 \mathrm{~Hz}$, $\mathrm{J} 2=14 \mathrm{~Hz}), 3.97(\mathrm{dd}, 1 \mathrm{H}, \mathrm{J} 1=3 \mathrm{~Hz}, \mathrm{~J} 2=14 \mathrm{~Hz}), 4.99-5.04(\mathrm{bm}, 2 \mathrm{H}), 7.43(\mathrm{~s}, 1 \mathrm{H}), 11.25(\mathrm{~s}$,

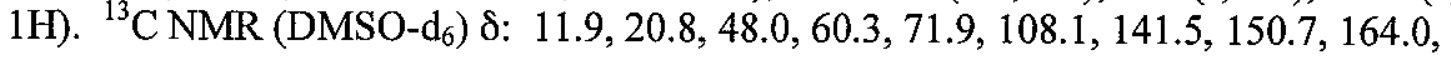
169.6

HRMS (EI) m/z $265.0791\left[\mathrm{M}+\mathrm{Na}^{+}\right.$; calcd for $\left.\mathrm{C}_{10} \mathrm{H}_{14} \mathrm{~N}_{2} \mathrm{O}_{5} \mathrm{Na}: 265.0793\right]$

$\lambda_{\max }(\mathrm{MeOH}): 268 \mathrm{~nm}$

\section{Compound (5)}

Compound 5 was prepared from 4 using the general phosphorylation and purification procedure as described ${ }^{1}$.

${ }^{32} \mathrm{P} \mathrm{NMR}\left(\mathrm{D}_{2} \mathrm{O}\right) \delta:-21.7(\mathrm{t}, \mathrm{J}=19 \mathrm{~Hz}),-9.8(\mathrm{~d}, \mathrm{~J}=19 \mathrm{~Hz}),-8.8(\mathrm{~d}, \mathrm{~J}=19 \mathrm{~Hz})$

(1) Ludwig, J.; Eckstein, F.; J. Org. Chem. 1989, 54, 631 


\section{4) gGTP Synthesis}<smiles>CC(C)OC[C@H](O)Cn1cnc2c(Cl)nc(N)nc21</smiles><smiles>CC(=O)O[C@H](CO)Cn1cnc2c(=O)[nH]c(N)nc21</smiles><smiles>CC(C)OCC(O)Cn1cnc2c(=O)[nH]c(N)nc21</smiles>

(a)2-Amino-6-chloropurine/ DMF/ 0.2 eq. $\mathrm{K}_{2} \mathrm{CO}_{3} /$ $85^{\circ} \mathrm{C} / 12 \mathrm{~h}$; (b) Conc. $\mathrm{HCl} / 1 \mathrm{~h} / 55^{\circ} \mathrm{C}$ (c) TMS-Cl pyridine/ isobutyric anhydride/ $\mathrm{NH}_{4} \mathrm{OH}$ (d) 1.1 eq. DMTr-Cl/ pyridine/ $12 \mathrm{~h} / \mathrm{rt}$; (e) 4 eq. Acetic anydride/ pyridine/ $2 \mathrm{~h} / \mathrm{rt}$; (d) Dichloroacetic acid/ $\mathrm{DCM} / 20 \mathrm{~min} / \mathrm{r}$; (e) i.) 1 eq. 2-chtoro-4H-1,3,2benzodioxaphosphorin-4-one/ dioxane/ pryridine/ $15 \mathrm{~min} . / \mathrm{rt} ; i$.) Tributylammonium pyrophosphate in DMF/ tributylamine/ $15 \mathrm{~min} / \mathrm{rt} ; i i i$ ) $1 \% \mathrm{I}_{2}$ in $98 / 2$ pyridine/ $\mathrm{H}_{2} \mathrm{O} / 15 \mathrm{~min} / \mathrm{r} ; \mathrm{iv}$.) $\mathrm{NH}_{4} \mathrm{OH} / 5 \mathrm{~h} / 55^{\circ} \mathrm{C}$; v.) Dowex $50 \mathrm{~W} \times 8 \mathrm{Na}+$

\section{Compound (6)}

2-Amino-6-chloropurine was dissolved in DMF and 0.2 eq. of $\mathrm{K}_{2} \mathrm{CO}_{3}$ were added. 1 eq. of R-(+)-glycidol was added slowly and reaction heated to $85^{\circ} \mathrm{C}$ for $24 \mathrm{~h}$. Solvent was removed and compound was purified on silica eluting with 85:15 DCM:MeOH in $82 \%$ yield as yellow powder.

Rf: 0.6 (DCM: MeOH; 80:20, v/v)

${ }^{1} \mathrm{H}$ NMR (DMSO-d $)$ ) $8: 3.41(\mathrm{~m}, 2 \mathrm{H}), 3.85(\mathrm{~m}, 1 \mathrm{H}), 3.94(\mathrm{dd}, 1 \mathrm{H}, \mathrm{J} 1=9 \mathrm{~Hz}, \mathrm{~J} 2=14 \mathrm{~Hz}$ ), $4.22(\mathrm{dd}, 1 \mathrm{H}, \mathrm{Jl}=3 \mathrm{~Hz}, \mathrm{~J} 2=14 \mathrm{~Hz}), 4.88(\mathrm{bs}, 1 \mathrm{H}), 5.12(\mathrm{bs}, 1 \mathrm{H}), 6.92(\mathrm{~s}, 2 \mathrm{H}), 8.05(\mathrm{~s}, 1 \mathrm{H})$.

${ }^{13}$ C NMR (DMSO-d d $_{6}$ ) : 46.5, 63.5, 69.2, 123.1, 143.9, 148.9, 154.0, 159.4

LRMS (EI) m/z 244.1 [M+H'; calcd for $\left.\mathrm{C}_{8} \mathrm{H}_{10} \mathrm{ClN}_{5} \mathrm{O}_{2} \mathrm{H}: 244.1\right]$

$\lambda_{\max }(\mathrm{MeOH}): 222,247,310 \mathrm{~nm}$

\section{Compound (7)}

Compound 6 was dissolved in concentrated $\mathrm{HCl}$ and heated to $55^{\circ} \mathrm{C}$ for $1 \mathrm{hr}$ followed by drying under vacuum to yield 7 in quantitative yield as a yellow powder. Rf: 0.54(DCM: MeOH; 50:50, v/v)

${ }^{1} \mathrm{H}$ NMR (DMSO-d $\left.)\right) \delta: 3.43(\mathrm{~m}, 2 \mathrm{H}), 3.87(\mathrm{~m}, 1 \mathrm{H}), 4.01(\mathrm{dd}, 1 \mathrm{H}, \mathrm{J} 1=9.2 \mathrm{~Hz}, \mathrm{~J}=14 \mathrm{~Hz})$, 4.31(dd, $1 \mathrm{H}, \mathrm{J} 1=3 \mathrm{~Hz}, \mathrm{~J} 2=14 \mathrm{~Hz}), 7.55(\mathrm{~s}, 2 \mathrm{H}), 9.20(\mathrm{~s}, 1 \mathrm{H}), 11.99(\mathrm{~s}, 1 \mathrm{H}) .{ }^{13} \mathrm{C} \mathrm{NMR}$ $\left(\right.$ DMSO-d $\left._{6}\right) \delta: 48.1,63.3,68.6,107.3,137.6,149.5,153.1,155.4$ LRMS (EI) m/z $226.08\left[\mathrm{M}+\mathrm{H}^{+}\right.$; calcd for $\left.\mathrm{C}_{8} \mathrm{H}_{11} \mathrm{~N}_{5} \mathrm{O}_{3} \mathrm{H}: 226.1\right]$ $\lambda_{\max }: \mathrm{MeOH} 254,283 \mathrm{~nm}$ 


\section{Compound (8)}

Compound 8 was prepared by transient amine protection of 7 using procedures outlined by Gait, M.J'.

Rf: 0.4 (DCM: $\mathrm{MeOH} ; 90: 10, \mathrm{v} / \mathrm{v})$

${ }^{1} \mathrm{H}$ NMR (DMSO-d $\left.)_{6}\right) \delta: 1.13(\mathrm{~s}, 3 \mathrm{H}), 1.15(\mathrm{~s}, 3 \mathrm{H}), 2.81(\mathrm{~m}, 1 \mathrm{H}, \mathrm{J}=7 \mathrm{~Hz}), 3.40(\mathrm{~m}, 2 \mathrm{H})$, 3.82(m, 1H), 3.96(dd, 1H, J1=9 Hz, J2=14 Hz), 4.24(dd, $1 \mathrm{H}, \mathrm{J} 1=4 \mathrm{~Hz}, \mathrm{~J} 2=14 \mathrm{~Hz}$ ), $4.92(\mathrm{t}, 1 \mathrm{H}, \mathrm{J}=6 \mathrm{~Hz}), 5.18(\mathrm{~d}, 1 \mathrm{H}, \mathrm{J}=6 \mathrm{~Hz}), 7.93(\mathrm{~s}, 1 \mathrm{H}), 11.72(\mathrm{~s}, 1 \mathrm{H}), 12.08(\mathrm{~s}, 1 \mathrm{H})$.

LRMS (EI) m/z $296.16\left[\mathrm{M}+\mathrm{H}^{+}\right.$; calcd for $\left.\mathrm{C}_{12} \mathrm{H}_{17} \mathrm{~N}_{5} \mathrm{O}_{4} \mathrm{H}: 296.13\right]$

$\lambda_{\max }(\mathrm{MeOH}): 256,281$

\section{Compound (9)}

Compound 8 was dissolved in pyridine and reacted with 1.1 eq of DMTr-Cl for $12 \mathrm{~h}$ at ambient temperature. Solvent was removed and coevaporated twice with toluene followed by silica gel chromatography eluting with 97:3:0.01 DCM:MeOH:TEA in 86\% yield as a white foam.

Rf: 0.3 (DCM: $\mathrm{MeOH} ; 97: 3, \mathrm{v} / \mathrm{v}$ )

${ }^{1} \mathrm{H}$ NMR $\left(\mathrm{CDCl}_{3}\right) \delta: 1.23(\mathrm{q}, 6 \mathrm{H}, \mathrm{J} 1=4, \mathrm{~J} 2=7 \mathrm{~Hz}), 2.78(5,1 \mathrm{H}, \mathrm{J}=7 \mathrm{~Hz}), 3.18(\mathrm{~m}, 2 \mathrm{H})$, 3.74(s, 6H), 4.07(dd, $1 \mathrm{H}, \mathrm{J} 1=9 \mathrm{~Hz}, \mathrm{~J} 2=14 \mathrm{~Hz}$ ), 4.20(dd, $1 \mathrm{H}, \mathrm{J} 1=3 \mathrm{~Hz}, \mathrm{~J} 2=14 \mathrm{~Hz}$ ), 4.32(bm, 1H), 6.7-7.4(aromatic, 14H), 11.68(s, 1H) LRMS (EI) m/z 598.1 [M+H $\mathrm{H}^{+}$; calcd for $\left.\mathrm{C}_{33} \mathrm{H}_{35} \mathrm{~N}_{5} \mathrm{O}_{6} \mathrm{H}: 598.3\right]$

$\lambda_{\max }(\mathrm{DCM}): 238,282 \mathrm{~nm}$

\section{Compound (10)}

Compound 9 was dissolved in pyridine and treated with 4 eq. of acetic anhydride for $2 \mathrm{~h}$ at ambient temperature. Pyridine was removed under vacuum and coevaporated twice with toluene the purified on silica gel eluting with 99:1:0.01 DCM:MeOH:TEA in 85\% yield as a white foam.

Rf: 0.7 (DCM: $\mathrm{MeOH} ; 90: 10, \mathrm{v} / \mathrm{v})$

${ }^{1} \mathrm{H}$ NMR $\left(\mathrm{CDCl}_{3}\right) \delta: 1.18(\mathrm{~d}, 3 \mathrm{H}, \mathrm{J}=1.6 \mathrm{~Hz}), 1.20(\mathrm{~d}, 3 \mathrm{H}, \mathrm{J}=1.2 \mathrm{~Hz}), 2.03(\mathrm{~s}, 3 \mathrm{H}), 2.61(\mathrm{~m}$, $1 \mathrm{H}), 3.08(\mathrm{dq}, 2 \mathrm{H}, \mathrm{J} 1=5 \mathrm{~Hz}, \mathrm{~J} 2=10 \mathrm{~Hz}, \mathrm{~J} 3=32 \mathrm{~Hz}), 3.37(\mathrm{~s}, 6 \mathrm{H}), 4.28(\mathrm{~d}, 2 \mathrm{H}, \mathrm{J}-5 \mathrm{~Hz})$, $5.20(\mathrm{t}, 1 \mathrm{H}, \mathrm{J}=\mathrm{Hz}), 6.7-7.3(\mathrm{~m}, 13 \mathrm{H}$, aromatic), 8.57(s, $1 \mathrm{H}), 9.77(\mathrm{~s}, 1 \mathrm{H}), 12.00(\mathrm{bs}, 1 \mathrm{H})$. ${ }^{13} \mathrm{C} \mathrm{NMR}\left(\mathrm{CDCL}_{3}\right) \delta: 19.2,21.1,36.3,43.7,55.4,62.0,70.6,86.5,113.2,120.7,127.0$, $127.9,129.8,135.2,135.3,139.3,144.2,147.7,148.7,155.6,158.5,169.7,179.1$

LRMS (EI) m/z 640.3 [M+H'; calcd for $\left.\mathrm{C}_{35} \mathrm{H}_{37} \mathrm{~N}_{5} \mathrm{O}_{7} \mathrm{H}: 640.3\right]$

$\lambda_{\max }(\mathrm{DCM}): 238,282$

\section{Comound (11)}

Compound 10 was dissolved in dry DCM and treated with 3\% DCAA at ambient temperature for $20 \mathrm{~min}$ followed by loading over silica and washing with three column volumes of DCM. Product eluted in 97:3 DCM:MeOH in 95\% yield as a white powder. Rf: 0.5 (DCM: MeOH; 90:10, v/v)

\footnotetext{
${ }^{2}$ Gait, MJ., ed. Oligonucleotide Synthesis: A Practical Approach. New York: Oxford University Press,
1990
} 
${ }^{1} \mathrm{H}$ NMR (DMSO-d $\left.\mathrm{d}_{6}\right) \delta: 1.12(\mathrm{~d}, 6 \mathrm{H}, \mathrm{J}=7 \mathrm{~Hz}), 1.92(\mathrm{~s}, 3 \mathrm{H}), 2.79(\mathrm{~m}, 1 \mathrm{H}), 3.52(\mathrm{bm}, 2 \mathrm{H})$, $4.29(\mathrm{dq}, 2 \mathrm{H}), 5.08(\mathrm{~m}, 1 \mathrm{H}), 5.13(\mathrm{t}, 1 \mathrm{H}, \mathrm{J}=6 \mathrm{~Hz}), 7.94(\mathrm{~s}, 1 \mathrm{H}), 11.71(\mathrm{~s}, 1 \mathrm{H}), 12.09(\mathrm{~s}, 1 \mathrm{H})$. ${ }^{13} \mathrm{C}$ NMR (DMSO-d $\mathrm{d}_{6}$ ) $\delta: 18.9,20.9,34.7,43.6,60.1,72.3,119.7,139.9,147.6,148.7$, $154.6,169.4,179.9$

HRMS (EI) m/z $338.1459\left[\mathrm{M}+\mathrm{H}^{+}\right.$; calcd for $\left.\mathrm{C}_{14} \mathrm{H}_{19} \mathrm{~N}_{5} \mathrm{O}_{5} \mathrm{H}: 338.1465\right]$

$\lambda_{\max }(\mathrm{MeOH}): 254,259,284 \mathrm{~nm}$

\section{Comound (12)}

Compound 12 was prepared using the general phosphorylation and purification procedures as described ${ }^{1}$.

${ }^{32} \mathrm{P}$ NMR $\left(\mathrm{D}_{2} \mathrm{O}\right) \delta$ : $-21.4(\mathrm{t}, \mathrm{J}=19.5 \mathrm{~Hz}),-9.8(\mathrm{~d}, \mathrm{~J}=19.4 \mathrm{~Hz}),=7.7(\mathrm{~d}, \mathrm{~J}=19.7 \mathrm{~Hz})$.

\section{3) gCTP Synthesis}<smiles></smiles><smiles></smiles>

(a)DMTr-Cl/ R-(+)-Glycido// DCM/ TEA $12 \mathrm{~h} / \mathrm{rt}$; (b) Benzoyl cytosine/ DMF/ 0.2 eq. NaH/ $120^{\circ} \mathrm{C} / 4 \mathrm{~h}$; (c) 4 eq. Ac $2 \mathrm{O} /$ pyridine $/ 3 \mathrm{~h} / \mathrm{rt}$ (d) Dichloroacetic acid/ DCM/ $20 \mathrm{~min} / \mathrm{rt}$; (e) $i$ ) 1 eq. 2-chloro-4H-1,3,2-benzodioxaphosphorin-4-one/ dioxane/ pryridine/ $15 \mathrm{~min} / \mathrm{rt}$; ii.) Tributylammonium pyrophosphate in DMF/ tributylamine/ $15 \mathrm{~min} / \mathrm{rt} ; \mathrm{iii}$.) $1 \% 12$ in 98/2 pyridine/ $\mathrm{H} 2 \mathrm{O} / 15 \mathrm{~min} . / \mathrm{rt} ; \mathrm{iv}$.) $\mathrm{NH}_{4} \mathrm{OH} / 8 \mathrm{~h} / 55^{\circ} \mathrm{C}$; v.) Dowex $50 \mathrm{WX} 8 \mathrm{Na}^{+}$

\section{Compound (13)}

$\mathrm{N}_{4}$-Benzoyl cytosine was dissolved in DMF at $120^{\circ} \mathrm{C}$ and reacted with 0.1 eq. of $\mathrm{NaH}$ for $1 \mathrm{hr}$ followed by addition of 1 eq. of O-DMTr-R-(+)-glycidol and reacted for $4 \mathrm{~h}$ at ambient temperature. Solvent was removed and reaction was purified on silica gel eluting with 98:2:0.01 DCM:MeOH:TEA giving a white foam in 35\% yield. ${ }^{1} \mathrm{H} \mathrm{NMR}\left(\mathrm{CDCl}_{3}\right) \delta: 3.12(\mathrm{dd}, 1 \mathrm{H}, \mathrm{J} 1=6, \mathrm{~J} 2=10 \mathrm{~Hz}), 3.26(\mathrm{dd}, 1 \mathrm{H}, \mathrm{J} 1=5.3 \mathrm{~Hz}, \mathrm{~J} 2=10 \mathrm{~Hz})$, $3.84(\mathrm{q}, 1 \mathrm{H}, \mathrm{J} 1=7 \mathrm{~Hz}, \mathrm{~J} 2=14 \mathrm{~Hz}$ ), $4.22(\mathrm{bs}, 1 \mathrm{H}), 4.35(\mathrm{dd}, 2 \mathrm{H}, \mathrm{J} 1=3 \mathrm{~Hz}, \mathrm{~J} 2=14 \mathrm{~Hz}), 6.8-$ $8.0($ aromatic, $20 \mathrm{H}), 8.73(\mathrm{bs}, 1 \mathrm{H})$ ${ }^{13} \mathrm{C} \mathrm{NMR}\left(\mathrm{CDCL}_{3}\right)$ 8: $(54.6,55.3,64.9,68.6,86.3,96.6,113.2,126.8,127.76,127.84$, $127.99,128.78,129.9,132.9,133.0,135.6,144.6,150.5,156.7,158.4,163.4,169.0$ 
LRMS (EI) $\mathrm{m} / \mathrm{z} 592.3\left[\mathrm{M}+\mathrm{H}^{+}\right.$; calcd. for $\left.\mathrm{C}_{35} \mathrm{H}_{33} \mathrm{~N}_{3} \mathrm{O}_{6} \mathrm{H}: 592.3\right]$

\section{Compound (14)}

Compound 13 was dissolved in pyridine and reacted with 4 eq. of acetic anhydride for $3 \mathrm{~h}$ followed by solvent removal and two coevaporations with toluene. Silica gel chromatography eluting in 99:1:0.01 DCM:MeOH:TEA gave product as a white foam in $92 \%$ yield.

Rf: 0.6 (DCM: $\mathrm{MeOH} ; 95: 5, \mathrm{v} / \mathrm{v})$

${ }^{1} \mathrm{H}$ NMR $\left(\mathrm{CDCl}_{3}\right) \delta:(1.99(\mathrm{~s}, 3 \mathrm{H}), 3.09(\mathrm{dd}, 1 \mathrm{H}, \mathrm{J} 1=4 \mathrm{~Hz}, \mathrm{~J} 2=16 \mathrm{~Hz}), 3.27(\mathrm{dd}, 1 \mathrm{H}, \mathrm{J} 1=4$ $\mathrm{Hz}, \mathrm{J} 2=10 \mathrm{~Hz}), 3.69(\mathrm{~s}, 6 \mathrm{H}), 3.91(\mathrm{dd}, 1 \mathrm{H}, \mathrm{J} 1=8 \mathrm{~Hz}, \mathrm{~J} 2=14 \mathrm{~Hz}), 4.37(\mathrm{dd}, 1 \mathrm{H}, \mathrm{J} 1=4 \mathrm{~Hz}$, $\left.\mathrm{J}_{2}=13 \mathrm{~Hz}\right), 5.26(\mathrm{~m}, 1 \mathrm{H}), 6.7-8.0\left(\mathrm{~m}, 18 \mathrm{H}\right.$, aromatic). $\left.{ }^{13} \mathrm{C} \mathrm{NMR}_{\left(\mathrm{CDCL}_{3}\right)}\right) \mathrm{d}: 21.0,50.1$, 53.6, 55.2, 62.3, 70.4, 86.3, 96.4, 113.2, 126.9, 127.6, 127.8, 128.8, 129.78, 129.82, $132.9,133.1,135.2,135.3,144.3,155.3,158.5,162.4,167.0,169.6$ LRMS (EI) $\mathrm{m} / \mathrm{z} 656.2\left[\mathrm{M}+\mathrm{Na}^{+}\right.$; calcd for $\mathrm{C}_{37} \mathrm{H}_{35} \mathrm{~N}_{3} \mathrm{O}_{7} \mathrm{Na}$ : 656.2] $\lambda_{\max }(\mathrm{DCM}): 238,258,313$

\section{Comound (15)}

Compound 14 was dissolved in dry DCM and treated with 3\% DCAA for 20 minute and loaded directly onto a silica gel column and washed with three column volumes of DCM and eluted in 97:3 DCM:MeOH giving 15 in $95 \%$ yield as a white powder.

Rf: 0.7 (DCM: $\mathrm{MeOH} ; 90: 110, \mathrm{v} / \mathrm{v})$

${ }^{1} \mathrm{H} \mathrm{NMR}\left(\mathrm{CDCl}_{3}\right) \delta: 2.10(\mathrm{~s}, 3 \mathrm{H}), 3.67(\mathrm{dd}, 2 \mathrm{H}, \mathrm{J} 1=4, \mathrm{~J} 2=13 \mathrm{~Hz}), 4.25(\mathrm{~d}, 2 \mathrm{H}, \mathrm{J}=5 \mathrm{~Hz})$, $5.16(\mathrm{~m}, 1 \mathrm{H}, \mathrm{J}=5 \mathrm{~Hz}), 7.5-7.7\left(\mathrm{~m}, 5 \mathrm{H}\right.$, aromatic), 7.94(d, 2H, J=8Hz). ${ }^{13} \mathrm{C}$ NMR $\left(\mathrm{CDCL}_{3}\right)$ $\delta: 21.3,50.1,60.5,72.4,97.6,127.8,129.0,132.9,132.3,133.3,150.0,156.7,163.0$, $166.8,170.3$

HRMS (EI) $\mathrm{m} / \mathrm{z} 332.1254\left[\mathrm{M}+\mathrm{Na}^{+}\right.$; calcd for $\left.\mathrm{C}_{16} \mathrm{H}_{17} \mathrm{~N}_{3} \mathrm{O}_{5} \mathrm{Na}: 332.1247\right]$

$\lambda_{\max }: \operatorname{DCM} 258,310 \mathrm{~nm}$

\section{Compound (16)}

Compound 16 was prepared using the general phosphorylation and purification methods as previously described .

${ }^{32}$ P NMR $\left(\mathrm{D}_{2} \mathrm{O}\right) \delta:-21.7(\mathrm{t}, \mathrm{J}=19 \mathrm{~Hz}),-9.8(\mathrm{~d}, \mathrm{~J}=19 \mathrm{~Hz}),-8.4(\mathrm{~d}, \mathrm{~J}=20 \mathrm{~Hz})$ 


\section{4) gATP Svthesis}<smiles>CC(=O)O[C@@H](COCC(C)C)Cn1cnc2c(C(C)(C)C)ncnc21</smiles>

(a) Adenine/ DMF/ 0.2 eq. NaH $/ 120^{\circ} \mathrm{C} / 6 \mathrm{~h}$; (b) 1.2 eq. Ac $2 \mathrm{O} /$ pyridine $/ 1 \mathrm{~h} / \mathrm{rt}$; (c) 3 eq. Benzoyl-Cl pyridine $/ 3 \mathrm{~h} / \mathrm{rt}$; (d) Dichloroacetic acid/ DCM/ $20 \mathrm{~min} / \mathrm{rt}$; (e) $i$.) 1 eq. 2-chloro-4H-1,3,2-benzodioxaphosphorin-4-one/ dioxane/ pyridine/ $15 \mathrm{~min} / \mathrm{rt}$;ii.) Tributylammonium pyrophosphate/ DMF/ tributylamine/ $15 \mathrm{~min} / \mathrm{rt} ;$ iii.) $1 \% \mathrm{I}_{2}$ in $98 / 2$ pyridine/ $\mathrm{H}_{2} \mathrm{O} / 15 \mathrm{~min} / \mathrm{rt} ; \mathrm{iv}$.) $\mathrm{NH}_{4} \mathrm{OH} / 5 \mathrm{~h} / 55^{\circ} \mathrm{C} ; \mathrm{v}$.) Dowex $50 \mathrm{WX} 8 \mathrm{Na}^{+}$

\section{Compound (17)}

Adenine was dissolved in $85^{\circ} \mathrm{C} \mathrm{DMF}$ and reacted with 0.1 eq. $\mathrm{NaH}$ for $2 \mathrm{~h}$ followed by addition of O-DMTr-R-( + -glycidol. After $24 \mathrm{~h}$ solvent removed and the reaction product purified on silica gel eluting with 94:4:0.01 DCM:MeOH giving white foam in $45 \%$ yield.

Rf: 0.6 (DCM: $\mathrm{MeOH} ; 90: 10, \mathrm{v} / \mathrm{v})$

${ }^{1} \mathrm{H}$ NMR $\left(\mathrm{CDCl}_{3}\right) \delta: 2.95(\mathrm{dd}, 1 \mathrm{H}, \mathrm{J} 1=9 \mathrm{~Hz}, \mathrm{~J} 2=9 \mathrm{~Hz}), 3.16(\mathrm{dd}, 1 \mathrm{H}, \mathrm{J} 1=6 \mathrm{~Hz}, \mathrm{~J} 2=10 \mathrm{~Hz})$, 3.67(s, 6H), 4.10(bm, 1H), 4.18(dd, $1 \mathrm{H}, \mathrm{J} 1=7 \mathrm{~Hz}, \mathrm{~J} 2=14 \mathrm{~Hz}), 4.32(\mathrm{dd}, 1 \mathrm{H}, \mathrm{J} 1=2 \mathrm{~Hz}$, $\mathrm{J} 2=14 \mathrm{~Hz}), 5.18(\mathrm{bs}, 1 \mathrm{H}), 5.80(\mathrm{bs}, 2 \mathrm{H}), 6.7-7.3(\mathrm{~m}, 13 \mathrm{H}$, aromatic $), 7.66(\mathrm{~s}, 1 \mathrm{H}), 8.16(\mathrm{~s}$, $1 \mathrm{H}) .{ }^{13} \mathrm{C} \mathrm{NMR}\left(\mathrm{CDCL}_{3}\right) \delta: 48.2,55.3,64.9,69.3,86.4,113.2,119.1,126.8,127.8$, $128.0,129.9,135.6,135.7,141.4,144.5,149.8,152.4,155.5,158.4$

LRMS (EI) m/z 512.0 [M+ $\mathrm{H}^{+}$; calcd for $\left.\mathrm{C}_{29} \mathrm{H}_{29} \mathrm{~N}_{5} \mathrm{O}_{4} \mathrm{H}: 512.2\right]$

$\lambda_{\max }(\mathrm{DCM}): 237,264 \mathrm{~nm}$

\section{Compound (18)}

Compound 17 was dissolved in pyridine and treated with 1.2 eq. of acetic acid which reacted primarily to give the acetylated hydroxyl product which after solvent removal and toluene coevaporations eluted from a silica gel column using 98:2:0.01

DCM:MeOH:TEA. Product was a white foam in $65 \%$ yield.

Rf: 0.3 (DCM: MeOH; 95:5, v/v)

${ }^{1} \mathrm{H}$ NMR $\left(\mathrm{CDCl}_{3}\right) \delta: 2.03(\mathrm{~s}, 3 \mathrm{H}), 3.25(\mathrm{~m}, 2 \mathrm{H}), 3.8(\mathrm{~s}, 6 \mathrm{H}), 4.54(\mathrm{qd}, 1 \mathrm{H}, \mathrm{J} 1=6 \mathrm{~Hz}, \mathrm{~J} 2=15$ $\mathrm{Hz}, \mathrm{J} 3=22 \mathrm{~Hz}), 5.34(\mathrm{~m}, 1 \mathrm{H}), 5.91(\mathrm{bs}, 2 \mathrm{H}), 6.8-7.4(\mathrm{~m}, 13 \mathrm{H}$, aromatic $), 7.73(\mathrm{~s}, 1 \mathrm{H})$, 8.32(s, $1 \mathrm{H}) .{ }^{13} \mathrm{C} \mathrm{NMR}\left(\mathrm{CDCL}_{3}\right) \delta: 21.2,43.9,55.4,62.2,71.1,86.5,113.3,119.6$, $127.0,127.9,129.88,129.91,135.38,135.41,140.7,144.3,150.2,153.0,155.6,158.6$, 169.8 
LRMS (EI) m/z $554.0\left[\mathrm{M}+\mathrm{H}^{+}\right.$; calcd for $\left.\mathrm{C}_{31} \mathrm{H}_{31} \mathrm{~N}_{5} \mathrm{O}_{5} \mathrm{H}: 554.2\right]$

$\lambda_{\max }(\mathrm{DCM}): 238,264 \mathrm{~nm}$

\section{Compound (19)}

Compound 18 was dissolved in pyridine and treated with 4 eq. of benzoyl-Cl for 4 $\mathrm{h}$ at ambient temperature. Solvent was removed and coevaporated twice with toluene before purifying by silica column using 99:1:0.01 TEA giving a white foam in 96\% yield. Rf: 0.5 (DCM: MeOH; 97:3, v/v)

${ }^{1} \mathrm{H} \mathrm{NMR}\left(\mathrm{CDCl}_{3}\right) \delta: 1.99(\mathrm{~s}, 3 \mathrm{H}), 3.24(\mathrm{~d}, 2 \mathrm{H}, \mathrm{J}=5 \mathrm{~Hz}), 3.78(\mathrm{~s}, 6 \mathrm{H}), 4.53(\mathrm{dd}, 1 \mathrm{H}, \mathrm{J} 1=7$ $\mathrm{Hz}, \mathrm{J} 2=15 \mathrm{~Hz}$ ), $4.66(\mathrm{dd}, 1 \mathrm{H}, \mathrm{J} 1=4 \mathrm{~Hz}, \mathrm{~J} 2=15 \mathrm{~Hz}), 5.30(\mathrm{bm}, 1 \mathrm{H}), 6.8-7.3$ (aromatic, $23 \mathrm{H}$ ), 8.03(s, $1 \mathrm{H}), 8.62(\mathrm{~s}, 1 \mathrm{H}) .{ }^{13} \mathrm{C} \mathrm{NMR}\left(\mathrm{CDCL}_{3}\right) \delta: 21.2,44.9,55.5,62.3,70.9,86.8$, $113.4,127.9,128.0,128.7,129.4,129.9,130.0,132.9,134.2,135.3,144.4,145.3,151.5$, $152.1,153.4,158.7,169.7,172.1$

LRMS (EI) $\mathrm{m} / \mathrm{z} 784 / 4\left[\mathrm{M}+\mathrm{Na}^{+}\right.$; calcd for $\mathrm{C}_{45} \mathrm{H}_{39} \mathrm{~N}_{5} \mathrm{O}_{7} \mathrm{Na}$ : 784.3]

$\lambda_{\max }(\mathrm{DCM}): 238,276 \mathrm{~nm}$

\section{Compound (20)}

Compound 19 was dissolved in dry DCM and treated with 3\% DCAA for 20 min followed by loading over silica gel column and washing with three column volumes of DCM. Product eluted in 97:3 DCM:MeOH giving a white powder in $94 \%$ yield. Rf: 0.4 (DCM: $\mathrm{MeOH} ; 95: 5, \mathrm{v} / \mathrm{v})$

${ }^{1} \mathrm{H} \mathrm{NMR}\left(\mathrm{CDCl}_{3}\right) \delta: 2.06(\mathrm{~s}, 3 \mathrm{H}), 3.45(\mathrm{dd}, 1 \mathrm{H}, \mathrm{J} 1=7 \mathrm{~Hz}, \mathrm{~J} 2=12.4 \mathrm{~Hz}), 3.66(\mathrm{dd}, 1 \mathrm{H}, \mathrm{J} 1=5$ $\mathrm{Hz}, \mathrm{J} 2=12.8 \mathrm{~Hz}$ ), $4.58(\mathrm{qd}, 2 \mathrm{H}, \mathrm{J} 1=4.4 \mathrm{~Hz}, \mathrm{~J} 2=15 \mathrm{~Hz}$ ), $5.17(\mathrm{bm}, 1 \mathrm{H}), 7.3-7.9$ (aromatic,

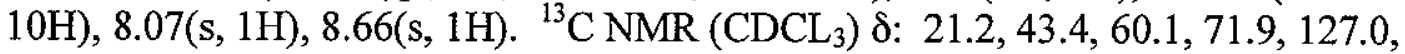
$128.8,129.5,133.1,134.0,145.7,152.1,153.4,169.9,172.2$

HRMS (EI) m/z $460.1597\left[\mathrm{M}+\mathrm{H}^{+}\right.$; calcd for $\left.\mathrm{C}_{24} \mathrm{H}_{21} \mathrm{~N}_{5} \mathrm{O}_{5} \mathrm{H}: 460.1622\right]$ $\lambda_{\text {max }}:$ DCM 250, 276

\section{Compound (21)}

Compound 21 was synthesized using the general phosphorylation and purification methods described previously ${ }^{1}$.

${ }^{32} \mathrm{P}$ NMR $\left(\mathrm{D}_{2} \mathrm{O}\right)$ 8: $-9.93(\mathrm{~d}, \mathrm{~J}=19 \mathrm{~Hz}),-9.75(\mathrm{~d}, \mathrm{~J}=19 \mathrm{~Hz}),-21.5(\mathrm{t}, \mathrm{J}=19 \mathrm{~Hz})$

\section{7) Polvmerase Experiments}

DNA oligomers for gNTP polymerase experiments were synthesized using by standard solid phase procedures. After ammonia treatment, DMTr-on oligomers were purified on a RP Pourus column followed by $10 \%$ acetic acid treatment and 2 water/ether extractions to remove trityl residue. Oligomers were further purified by $15 \%$ denaturing PAGE followed by electroelution and ethanol precipitation. To test purity, the oligomers were ${ }^{32} \mathrm{P}$-end-labeled and analyzed by $20 \%$ denaturing PAGE. Typical primer extension reactions were carried out in $20 \mu \mathrm{l}$ volume in a heated lid thermocycler. Buffers conditions, triphosphate concentrations, and temperatures are all listed in the figure captions. 
Oligonucleotide primers were ${ }^{32} \mathrm{P}$-end-labeled using T4 PNK (New England Biolabs, Beverley, MA) and $\gamma$ P32 ATP (MP, Irvine, CA) for $1 \mathrm{~h}$ at $37^{\circ} \mathrm{C}$ followed by heat denaturing at $95^{\circ} \mathrm{C}$ for $15 \mathrm{~min}$. Excess $\gamma^{32} \mathrm{P}$ ATP was removed using Micro-Spin G25 size exclusion columns (Amersham-Bioscience, Buckinghamshire, England) and quantitated by UV. Primer and template were annealed by heating to $95^{\circ} \mathrm{C}$ followed by slow cooling to room temperature. Polymerase reactions each contained $250 \mathrm{nM}$ duplex DNA. Reactions were initiated after 5 min of preheating by the addition of a 2X NTP solution to the annealed primer/template and polymerase. Reactions were quenched using stop buffer (8M urea, $100 \mathrm{mM}$ EDTA, Bromophenol Blue, and Xylene Cyanol) and analyzed by $20 \%$ (19:1) denaturing PAGE. Gel imaging was done using Kodak-K radioisotope screen and a Bio-Rad FX molecular imager. 


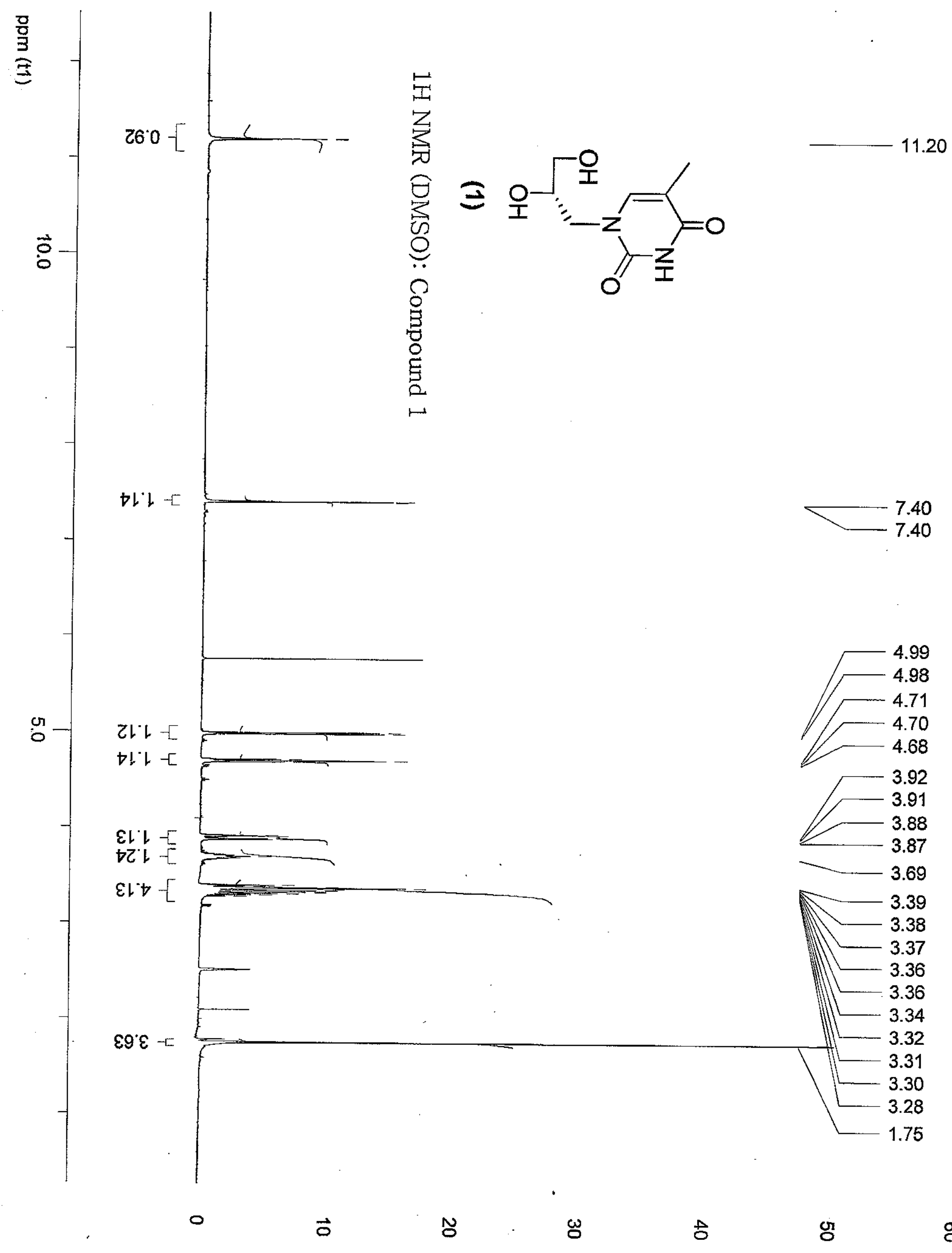




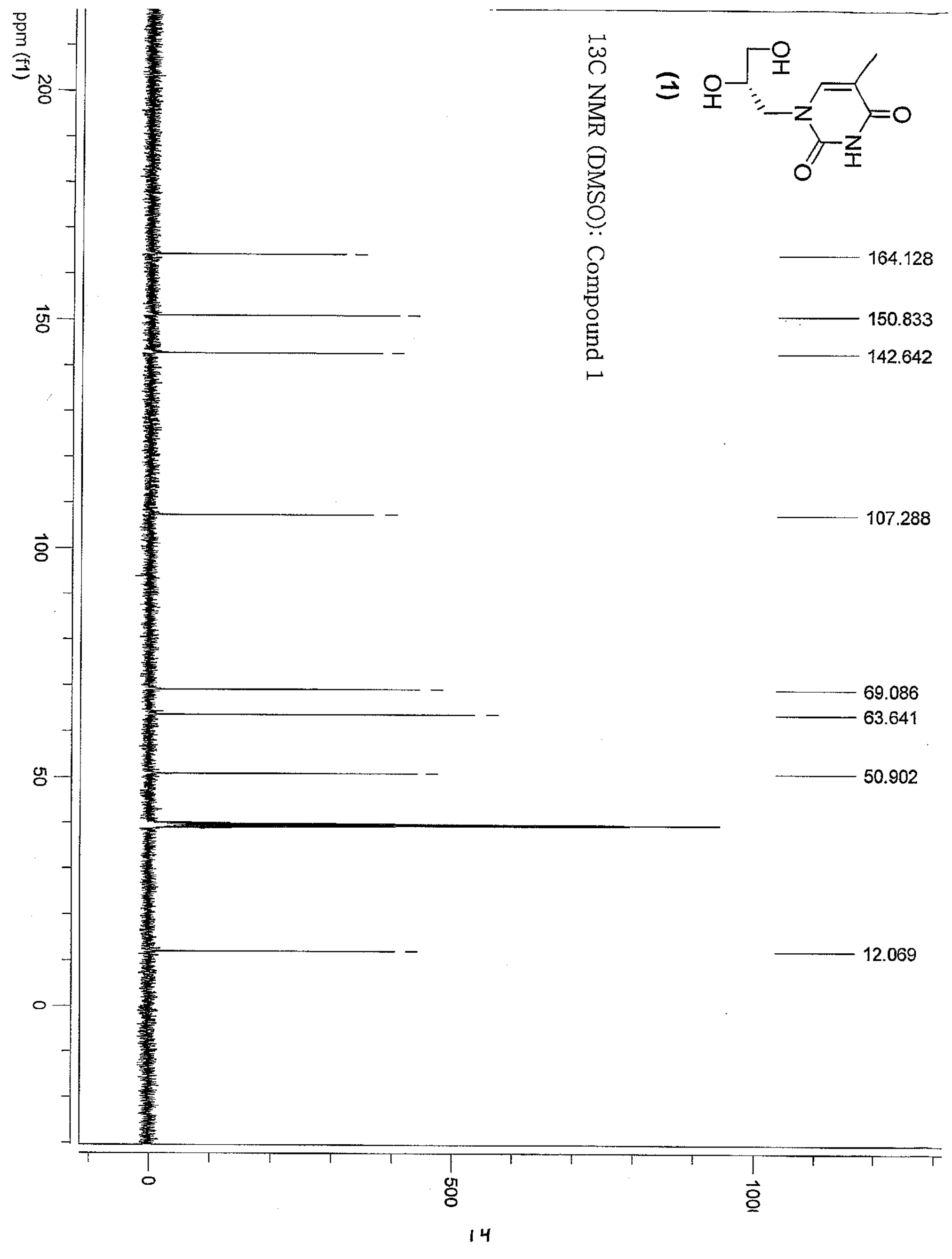




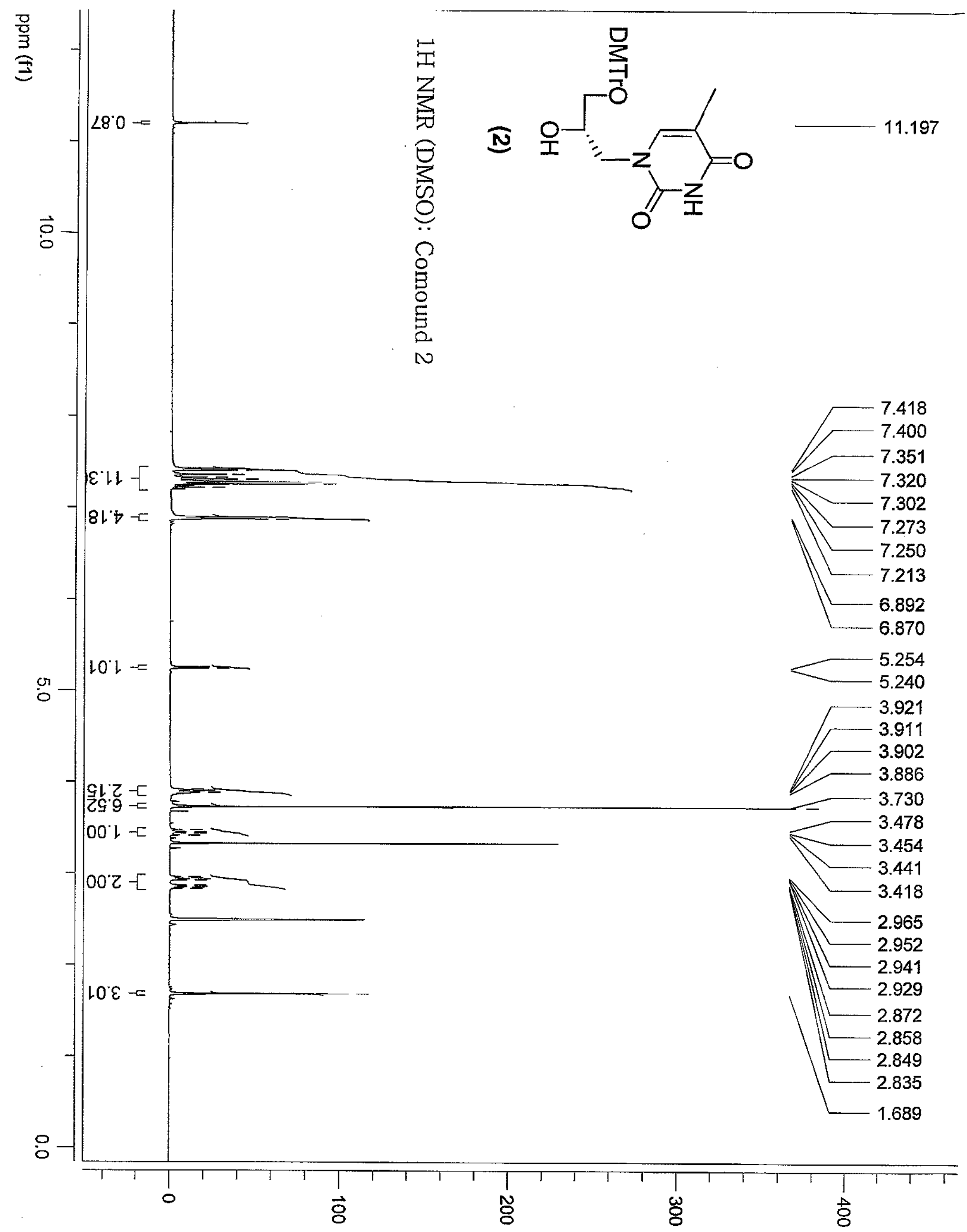




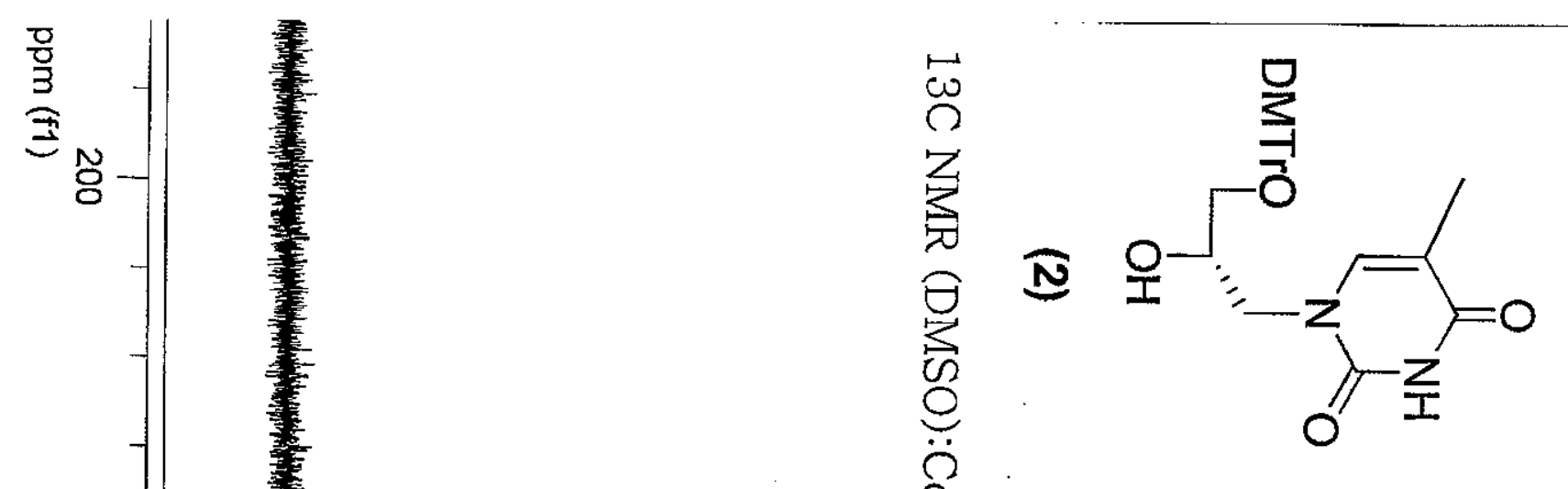

$-164.104$

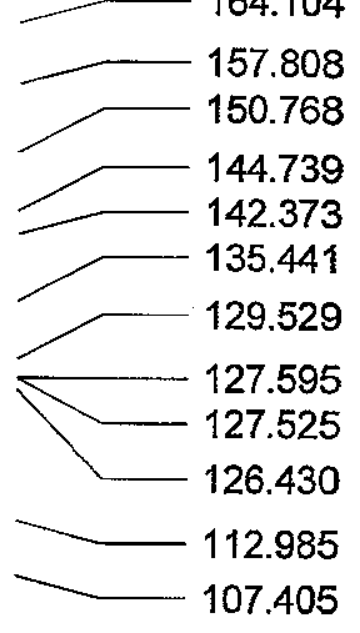

$\overrightarrow{8}$

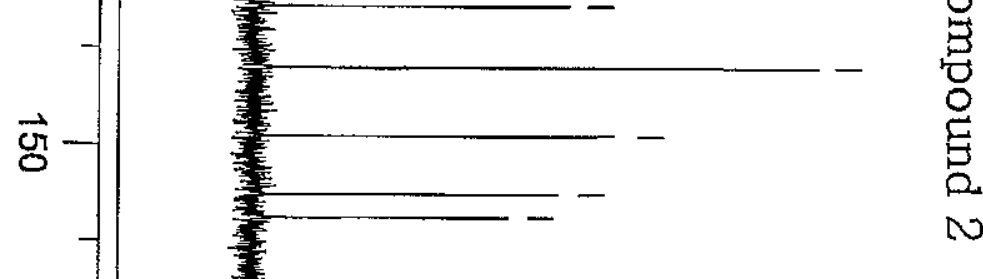

85.269

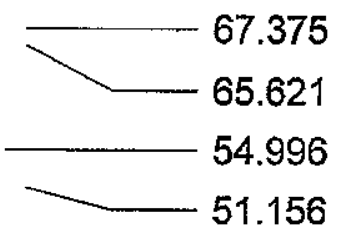

12.040

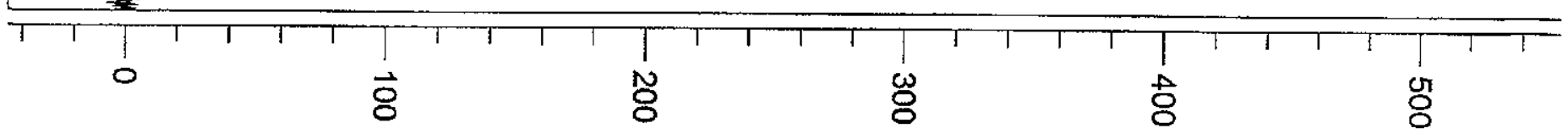




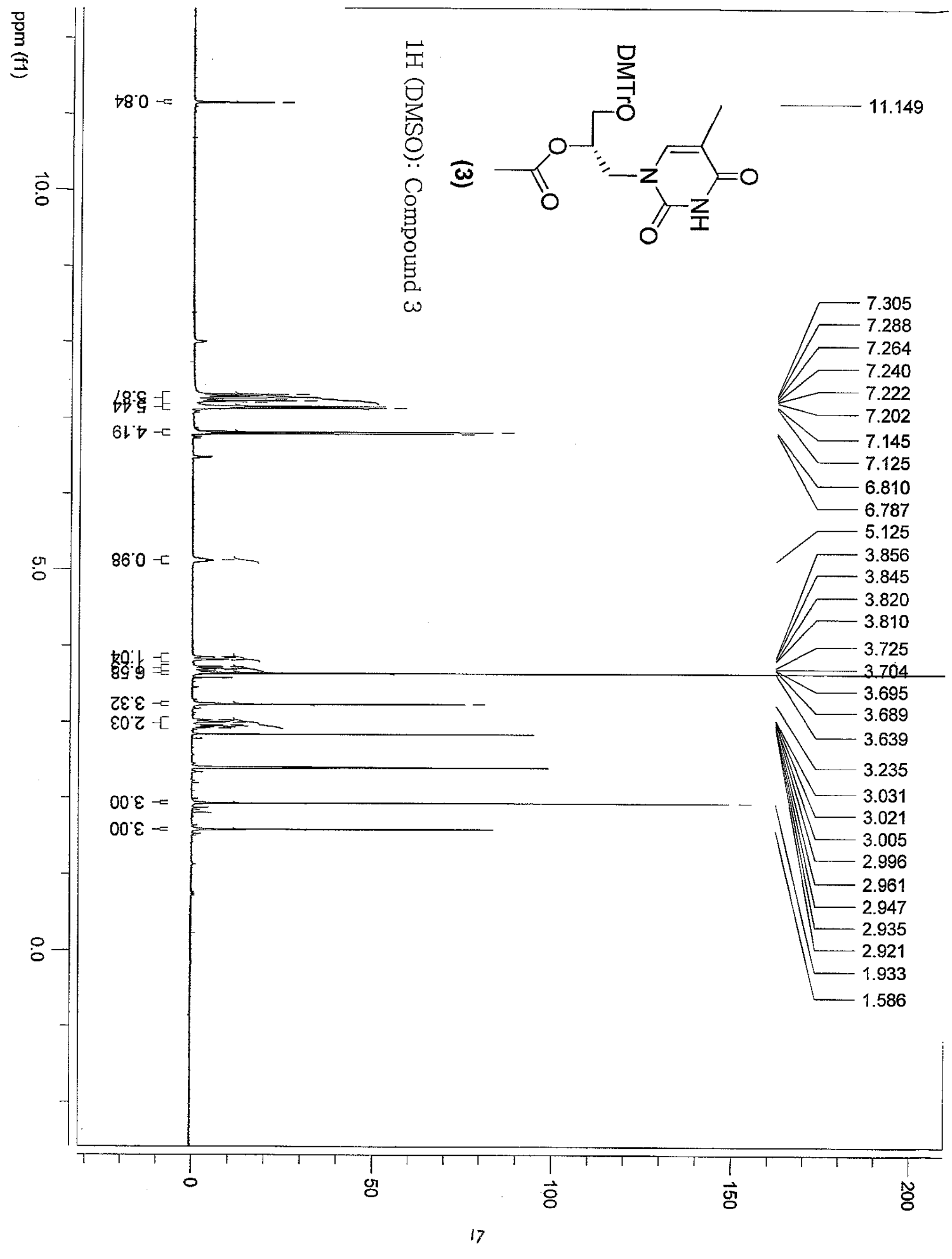




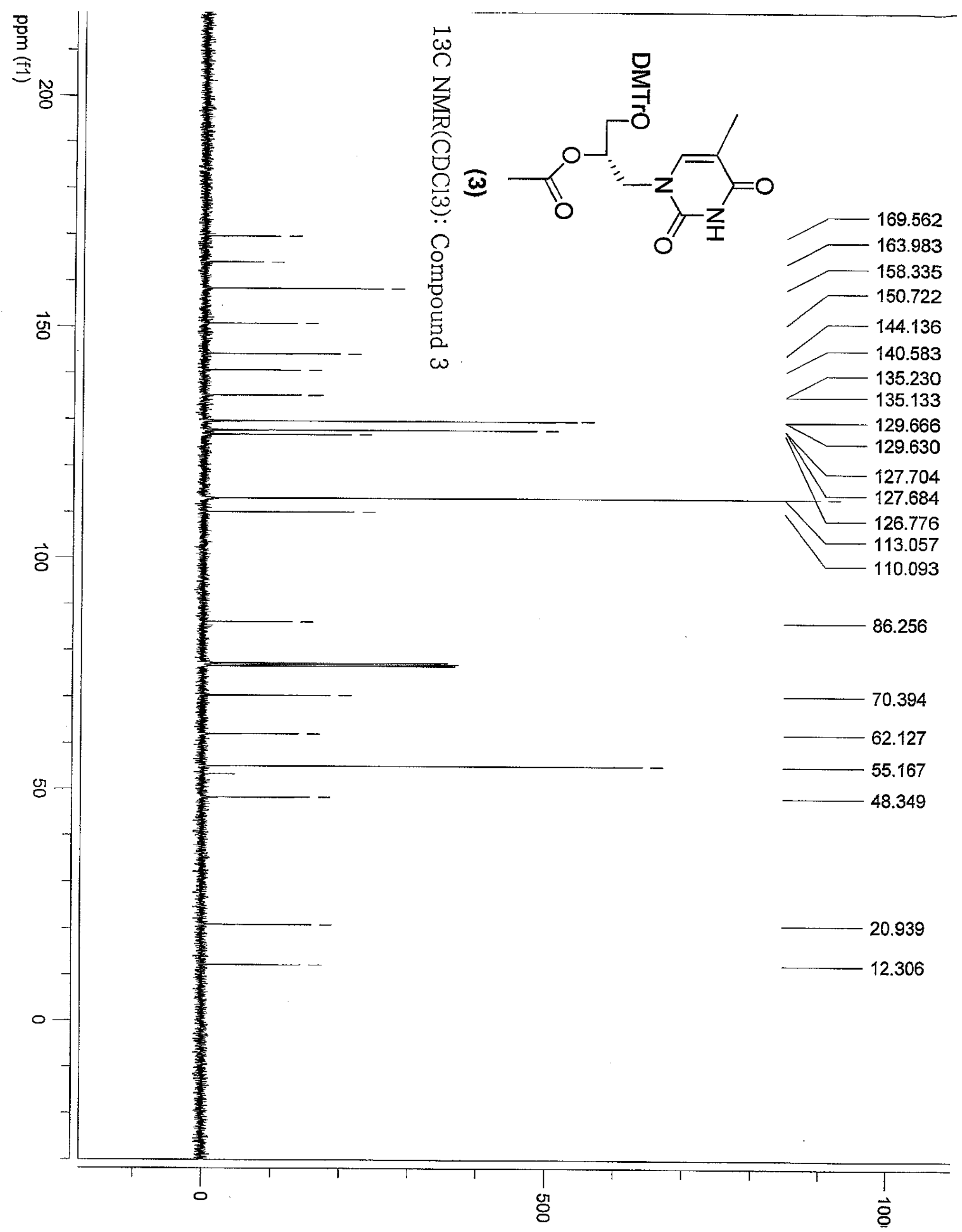




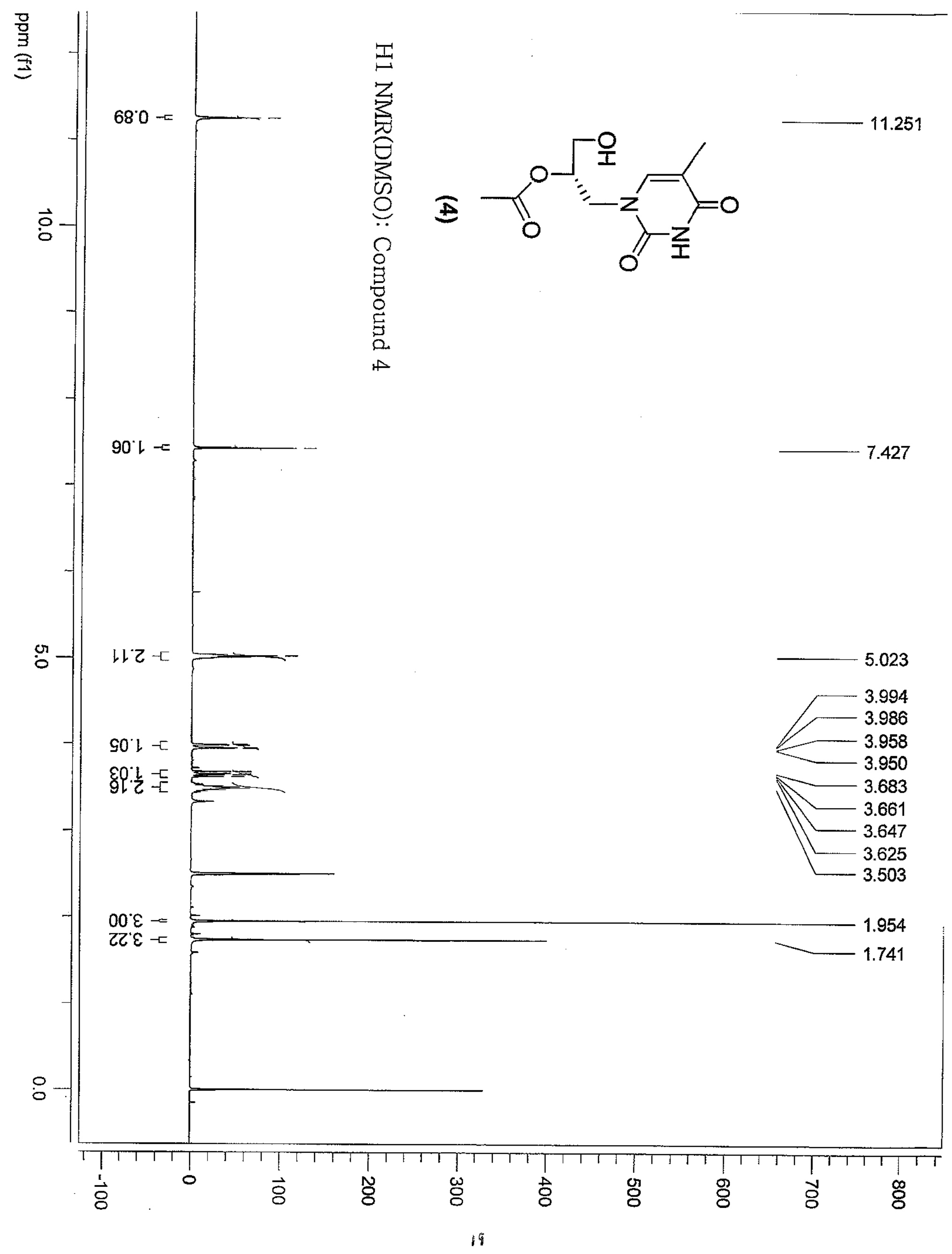




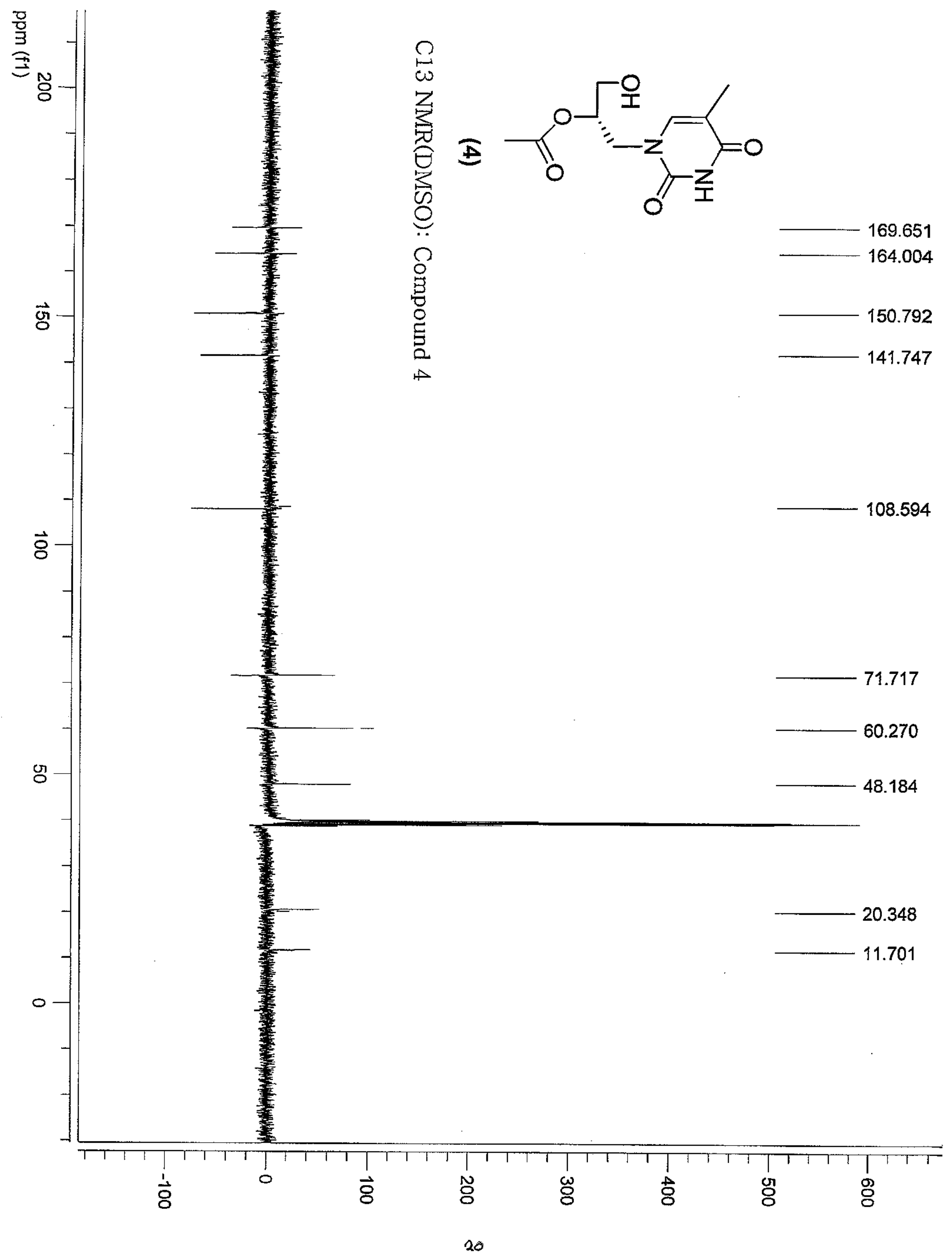




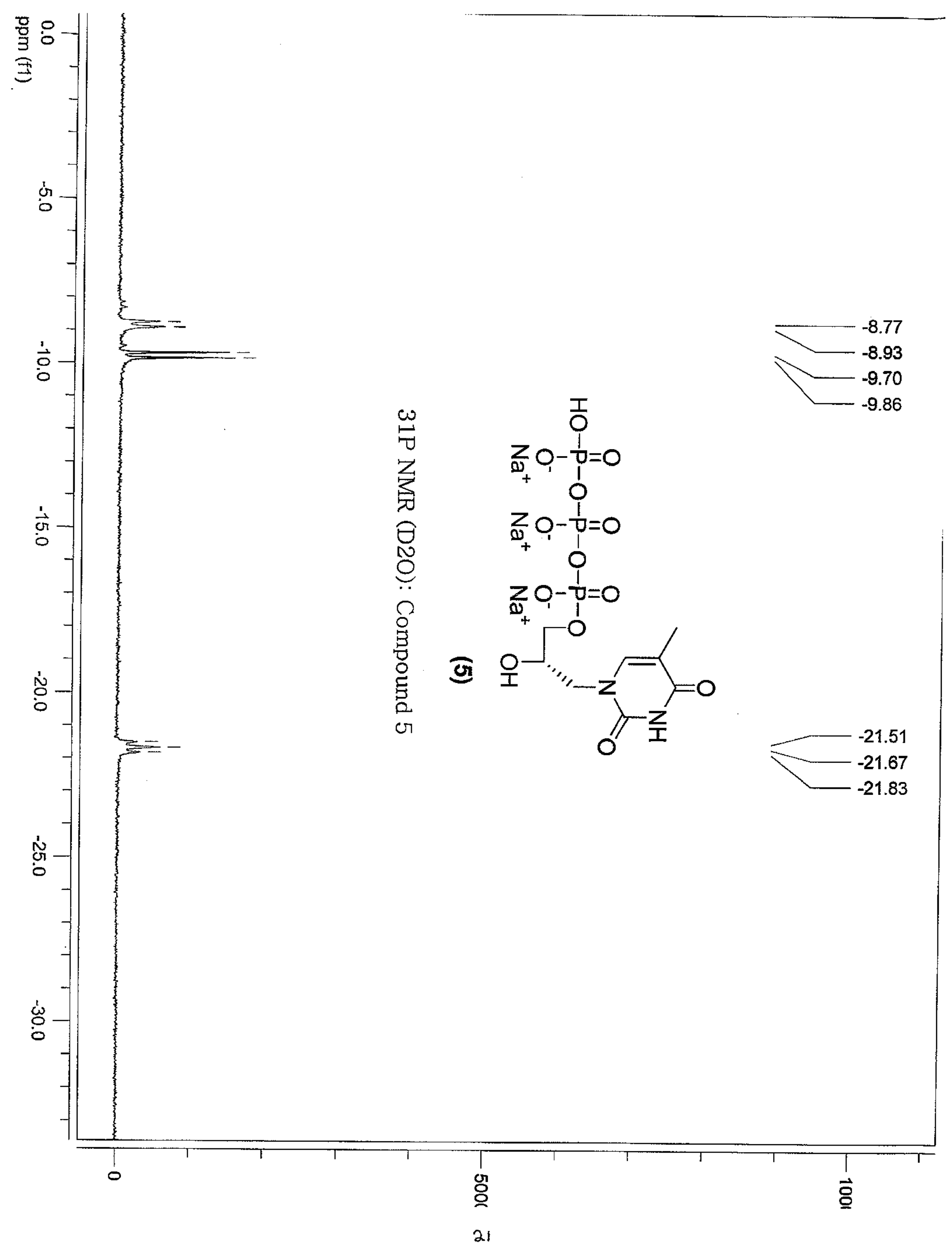




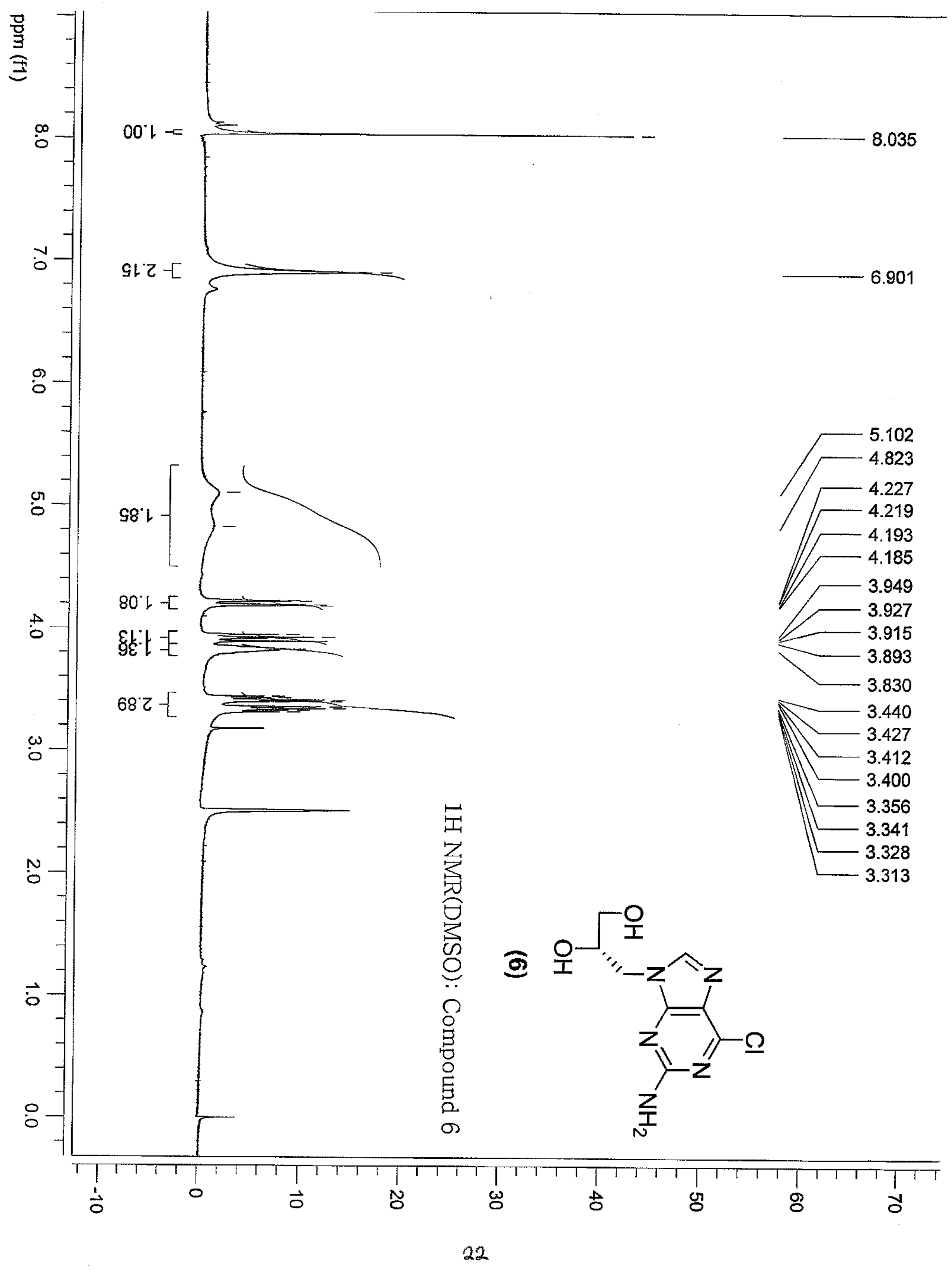




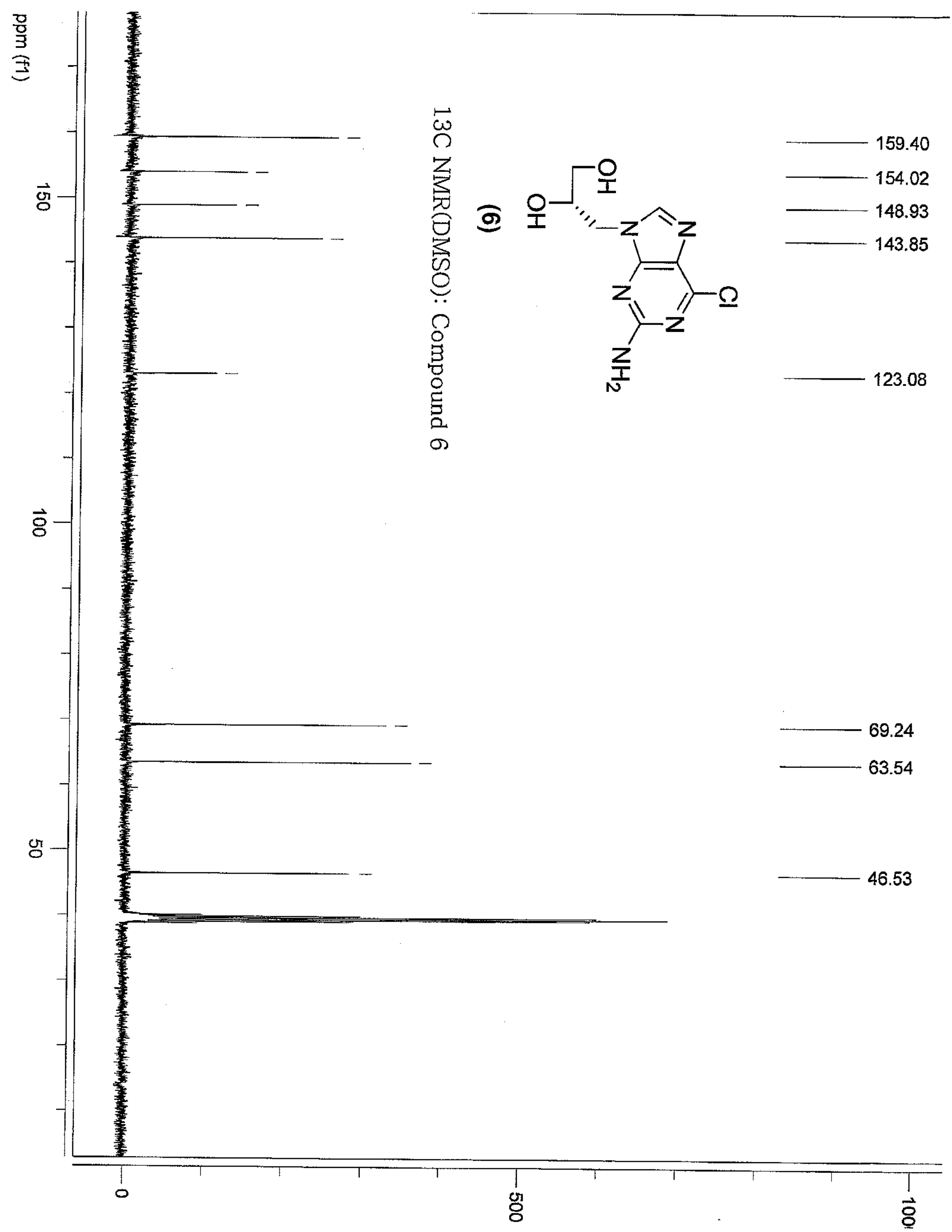


응

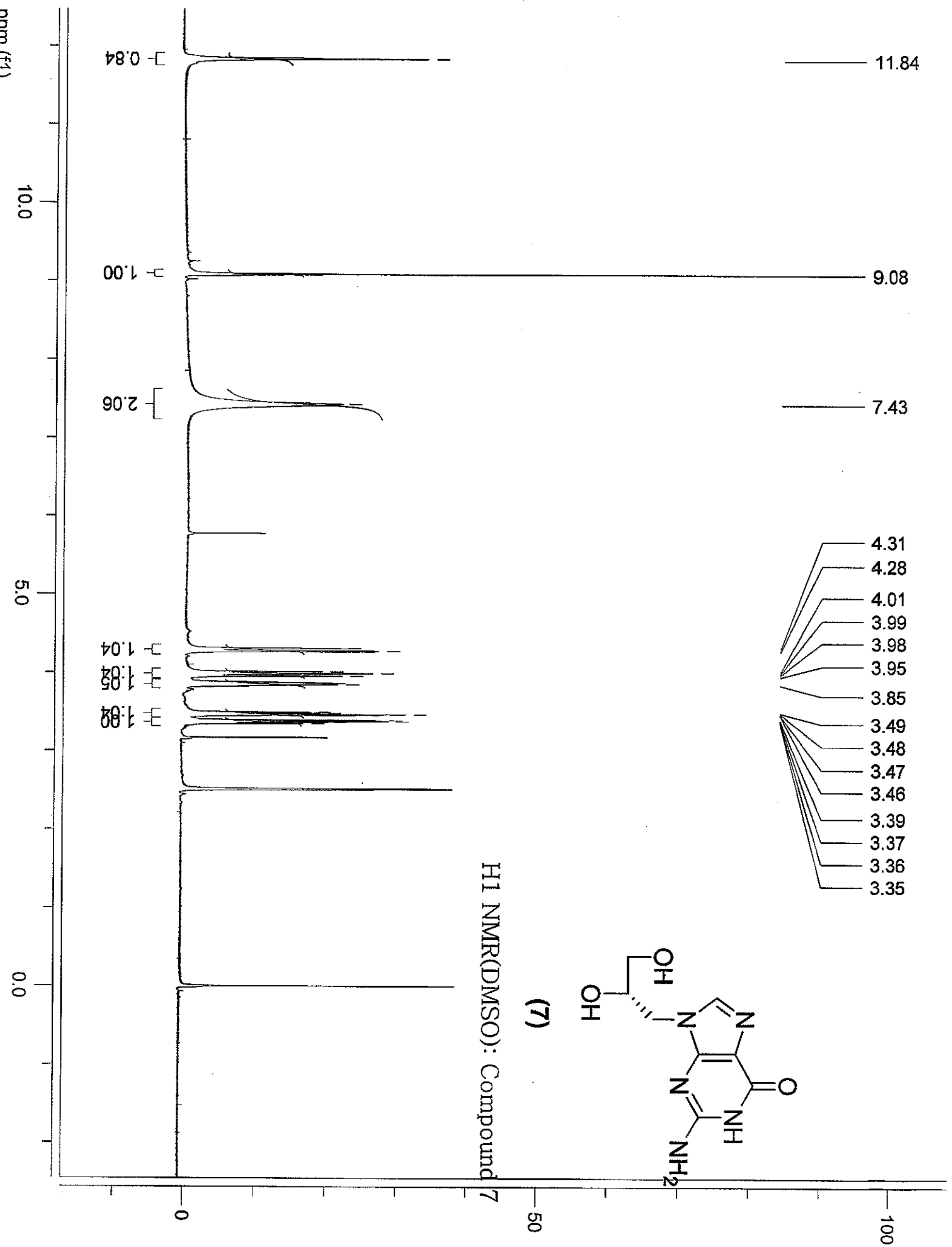




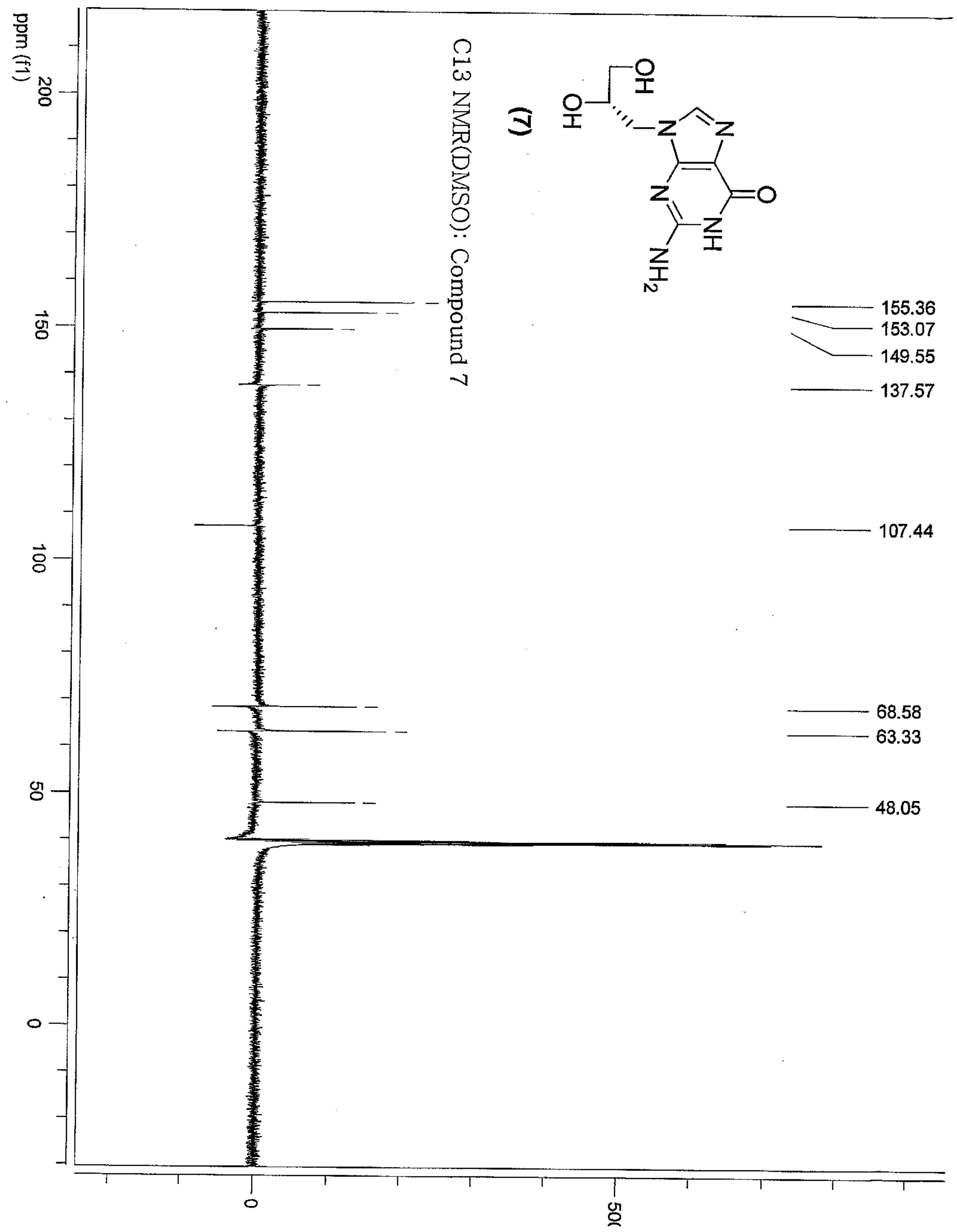


宭

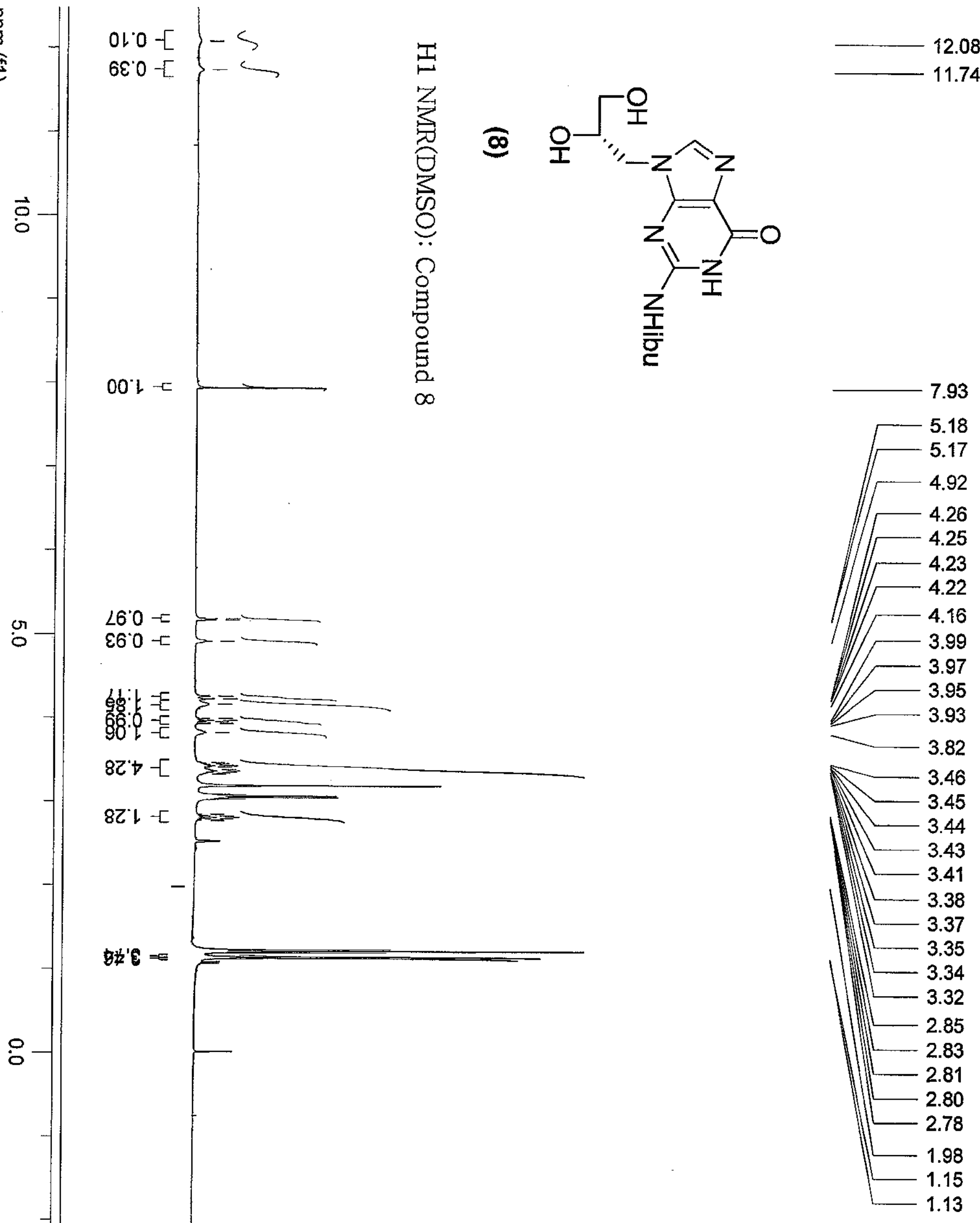


$\frac{\sqrt[0]{3}}{3}$

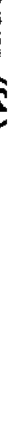

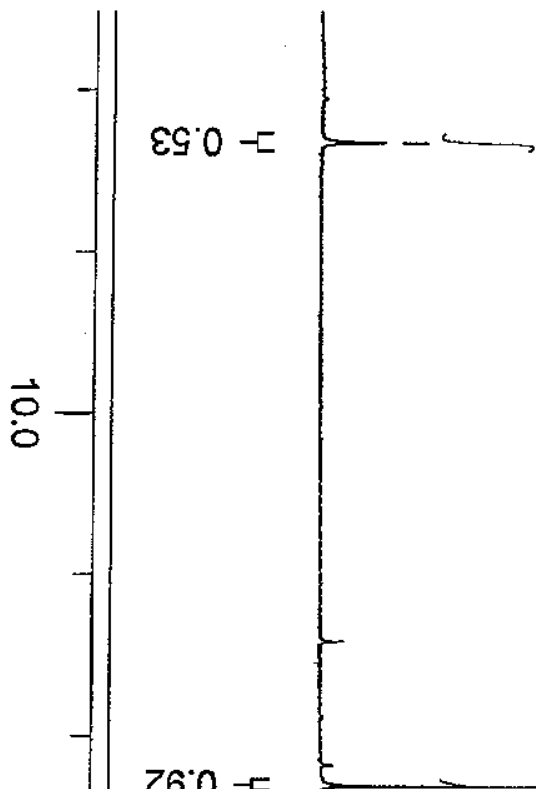

$260-5$

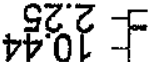

LE'

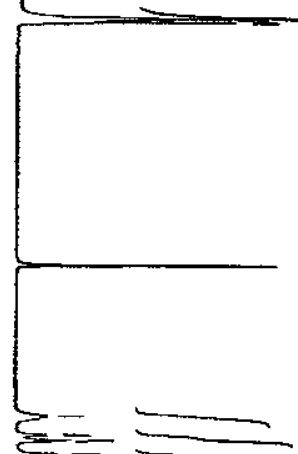

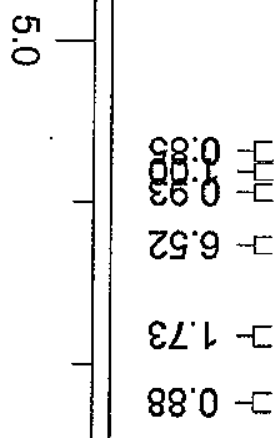

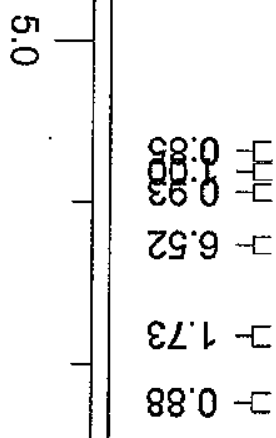

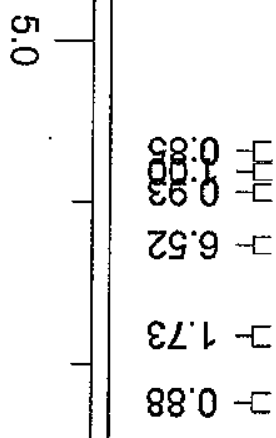

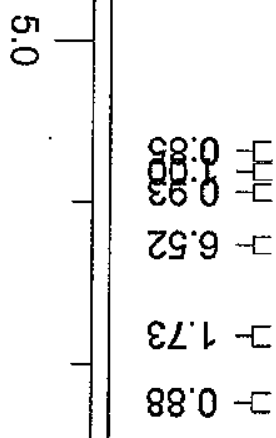

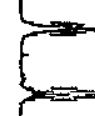

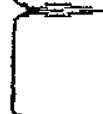

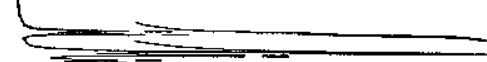

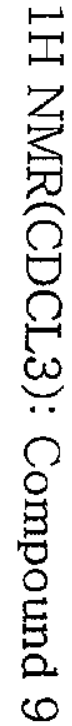<smiles>C1O[Co]1</smiles><smiles>[CH]OC(C)C</smiles>

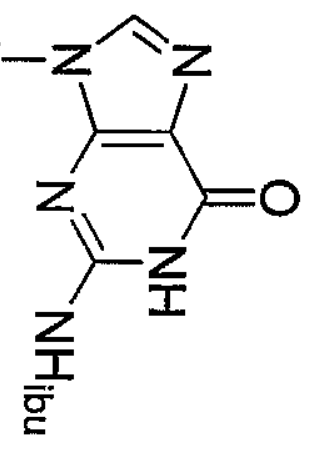

0
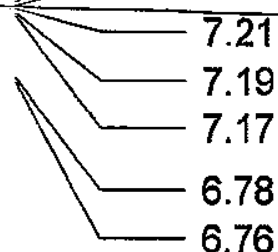

$-1$

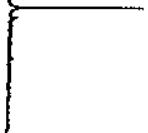

$89^{\circ} 9-[$
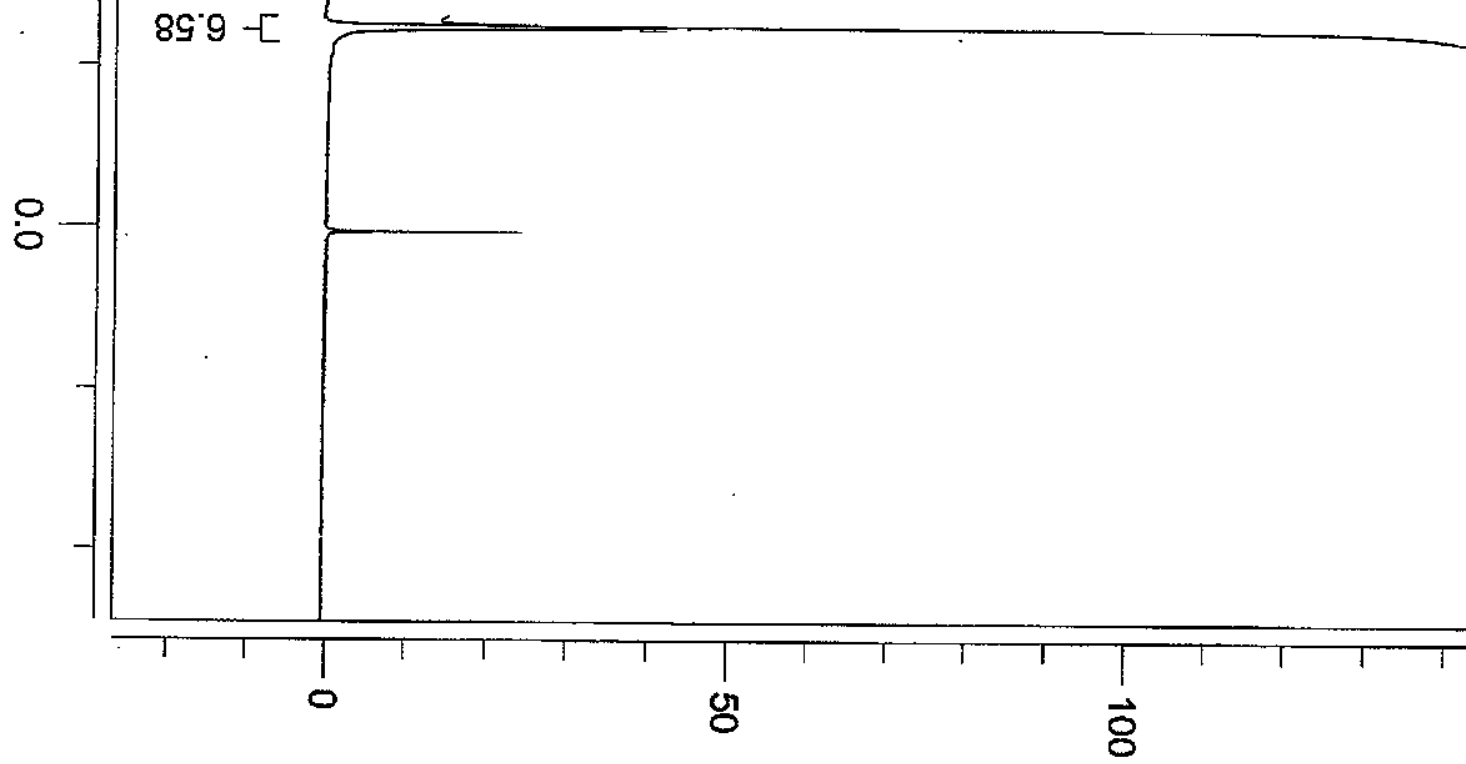


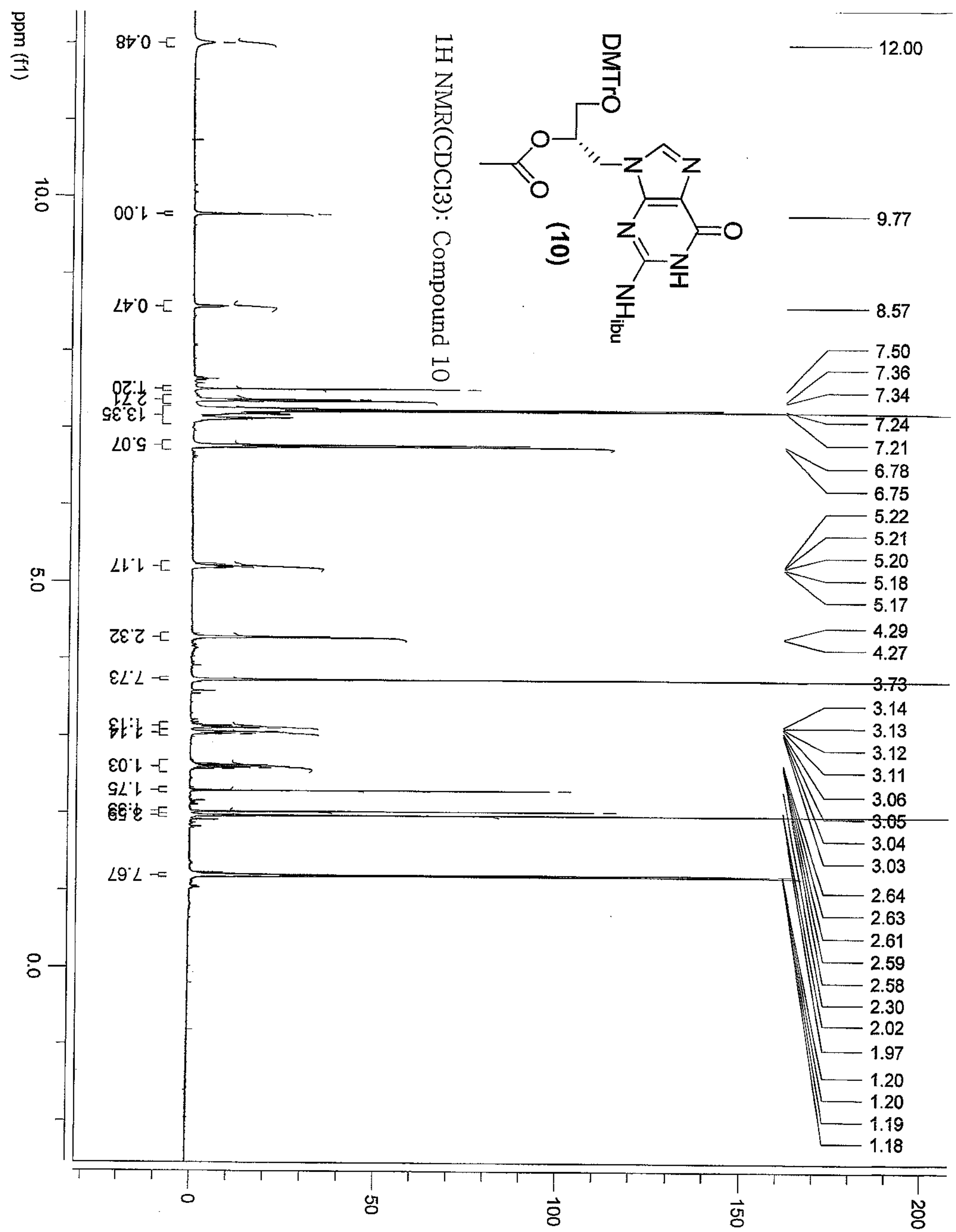




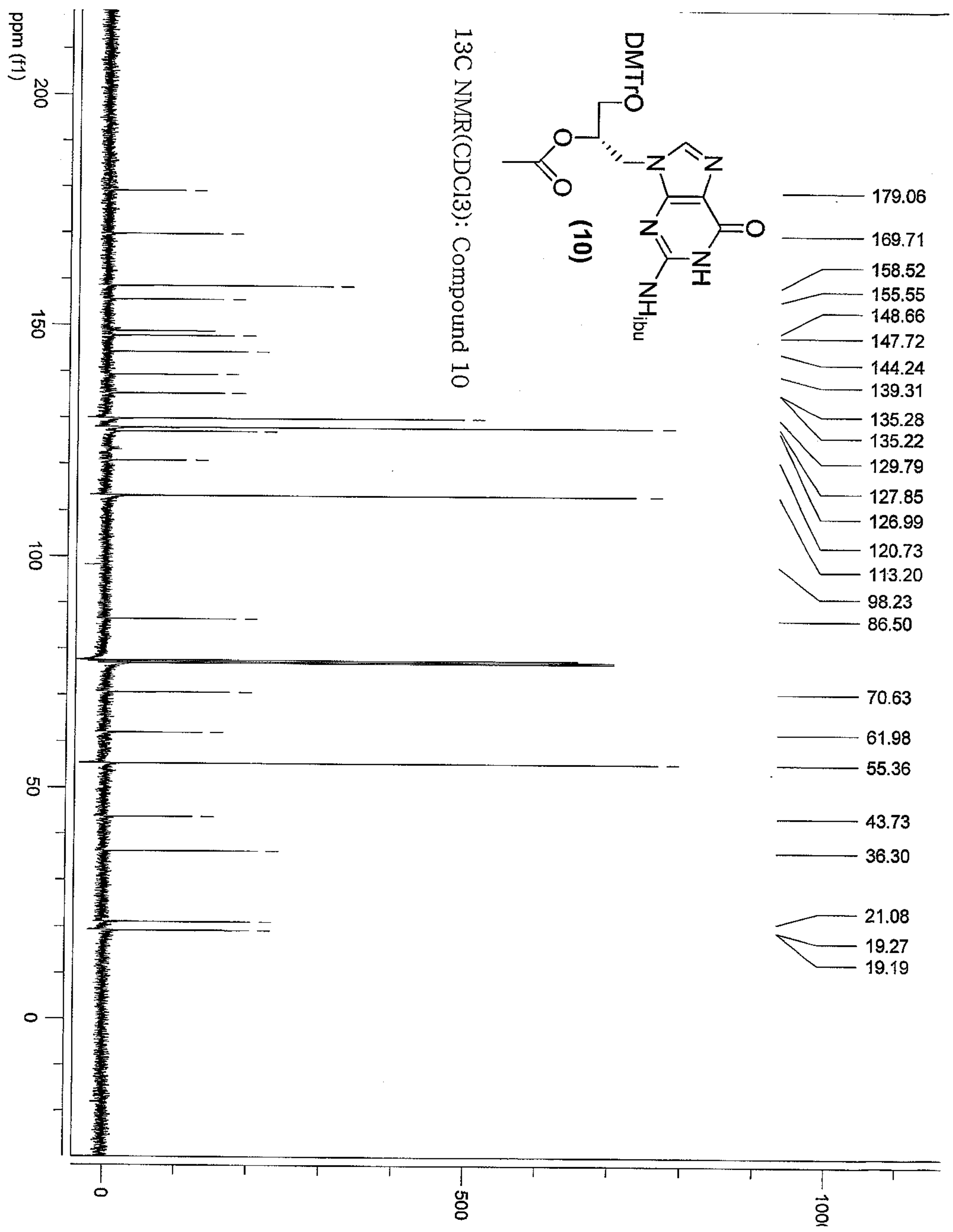




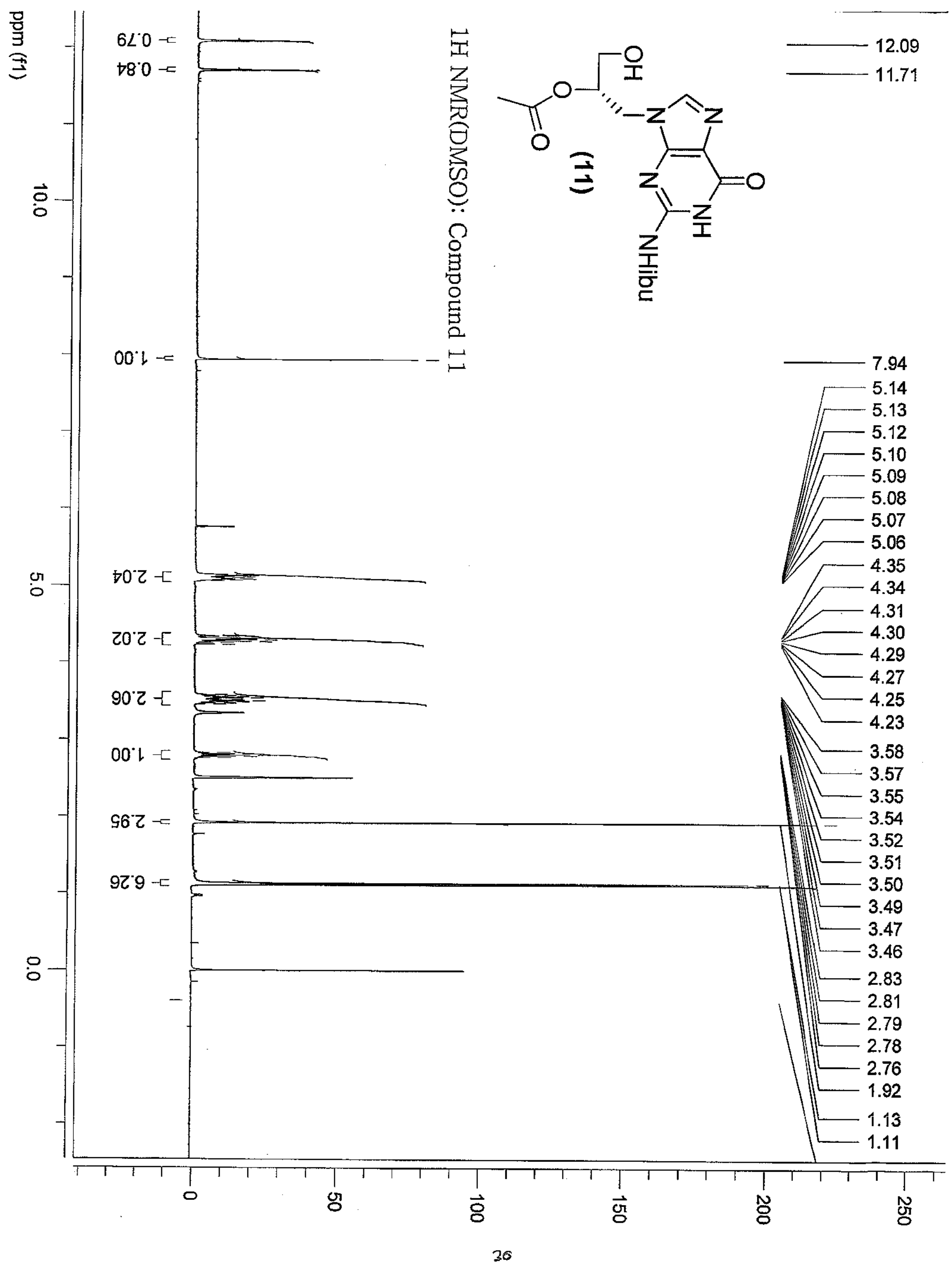




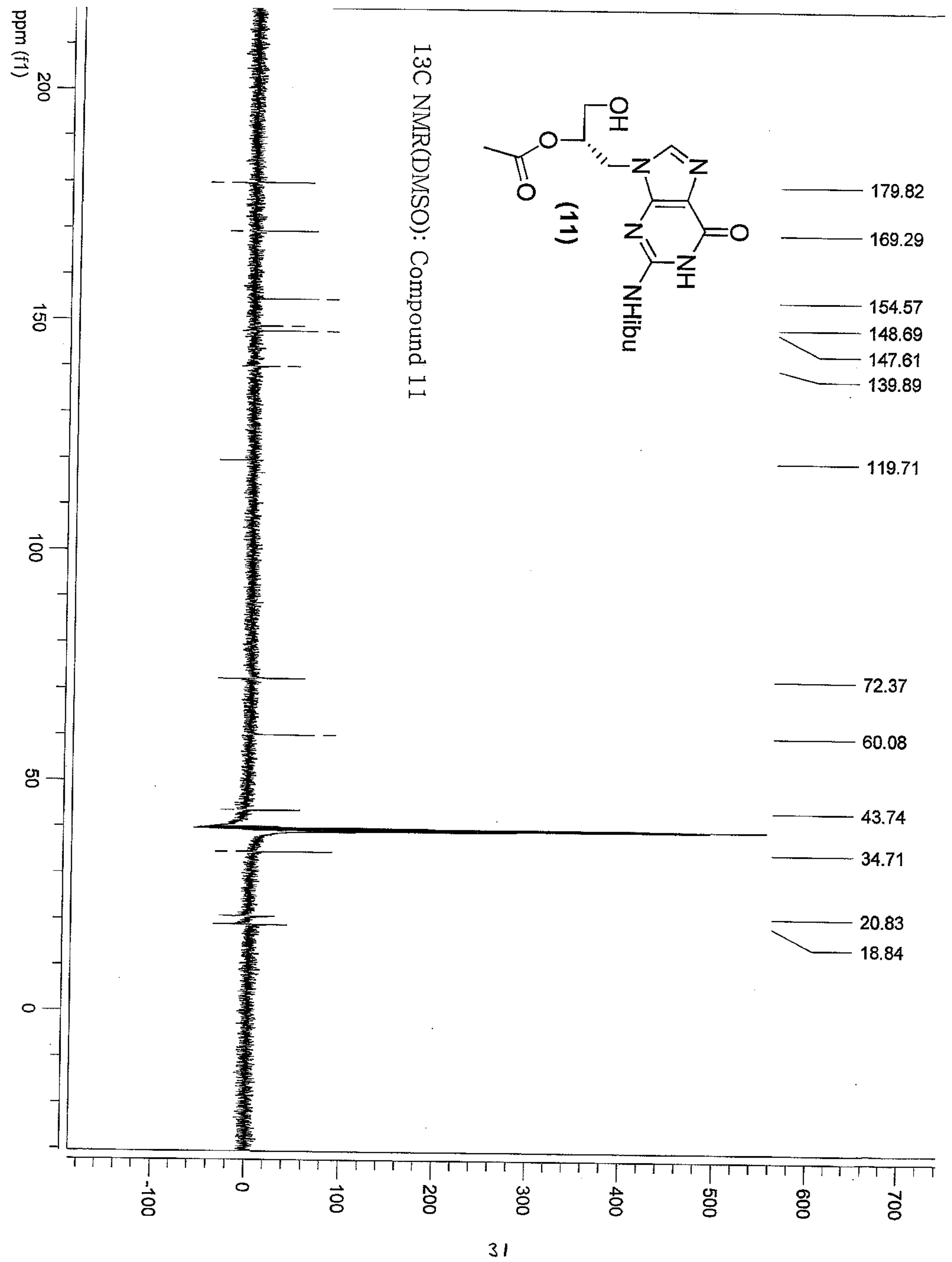




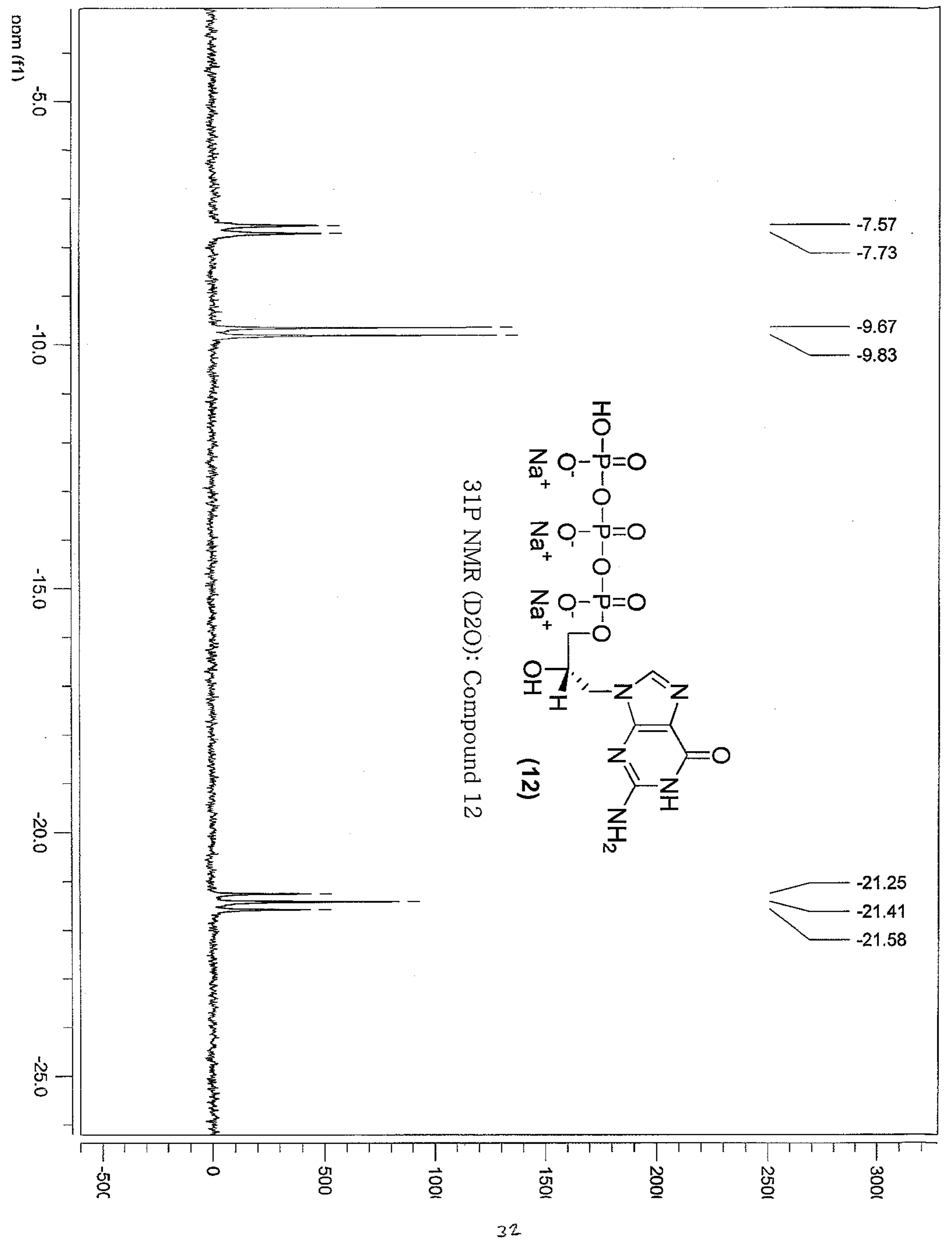


咅

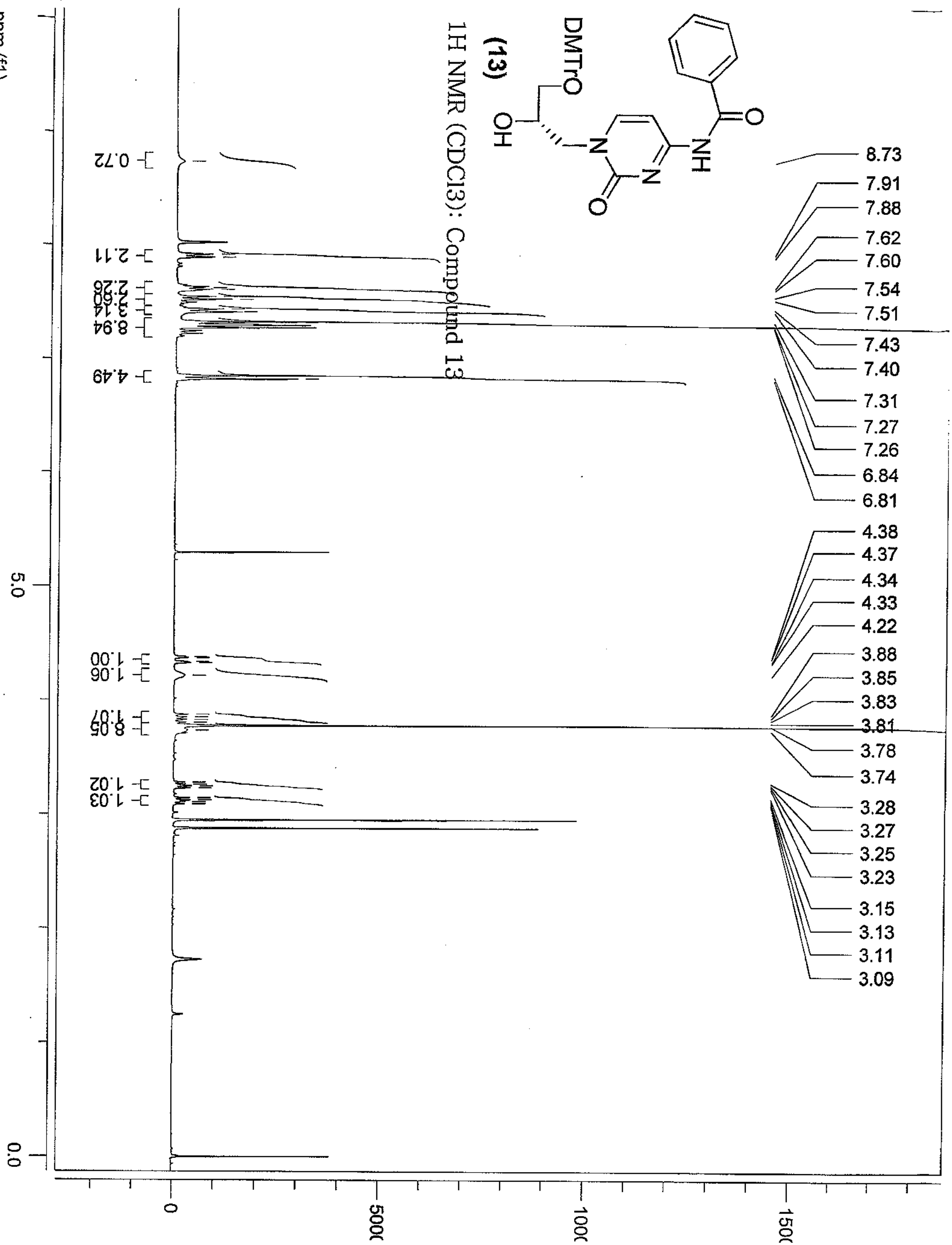


章

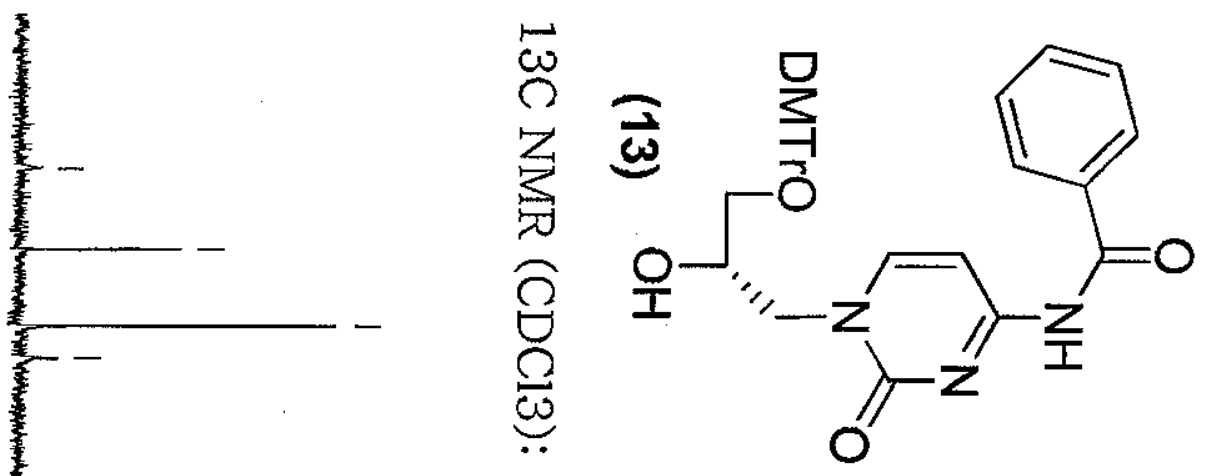

$\overrightarrow{0}$

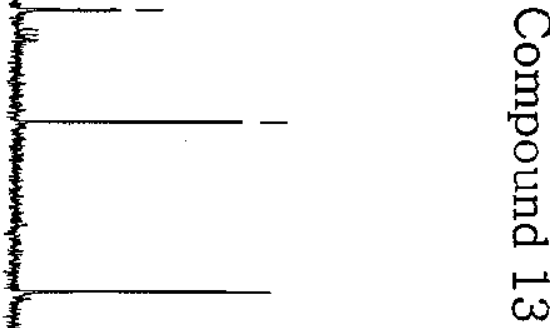

166.43

162.19

158.15

156.46

150.20

144.32

135.40

132.78

132.66

129.70

128.54

127.74

127.59

127.51

126.56

112.93

96.31

86.03

68.38

64.62

55.06

54.38

53.38

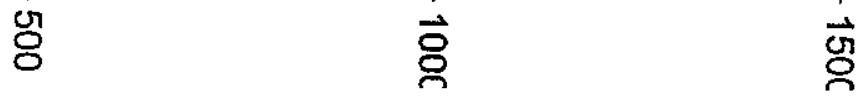




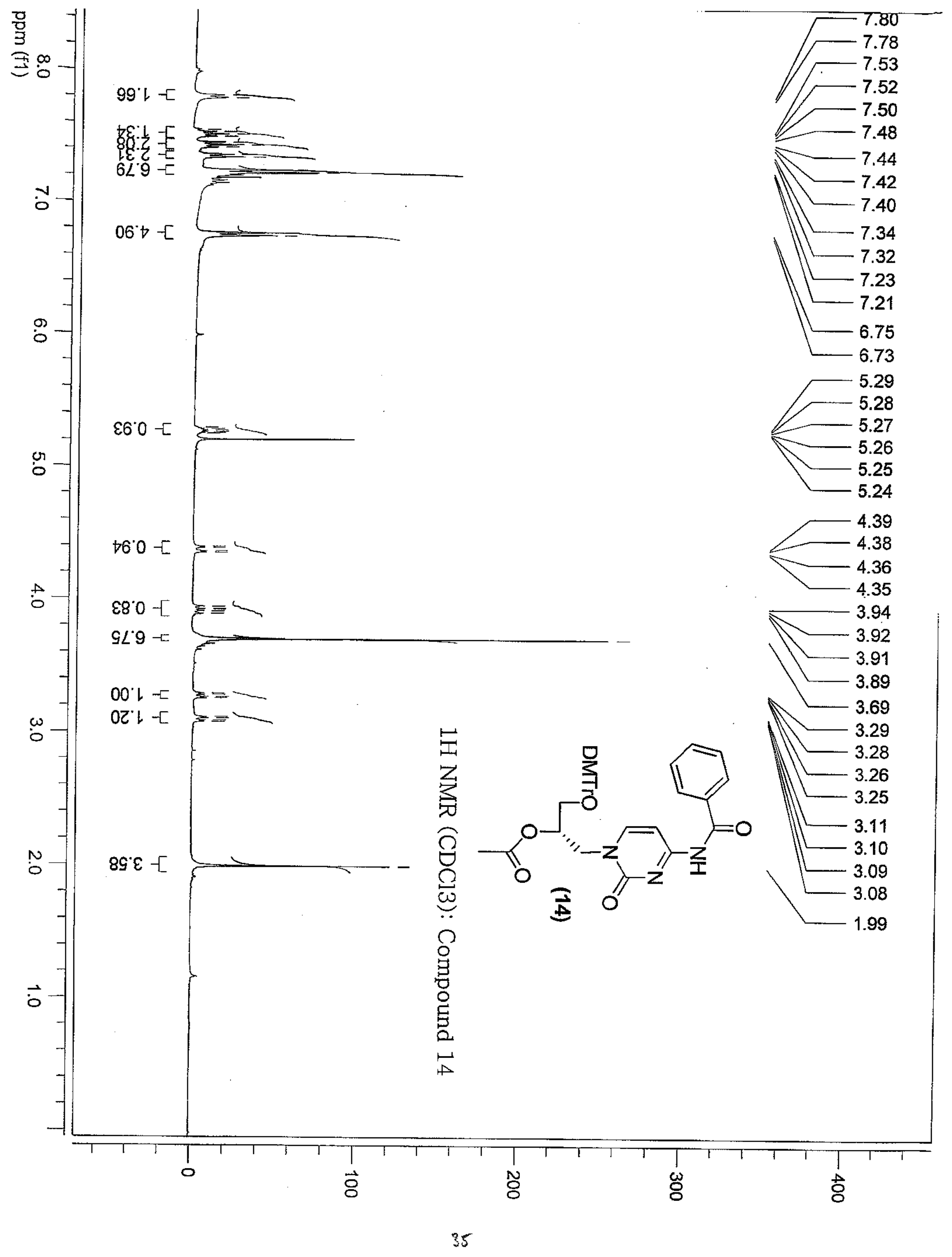




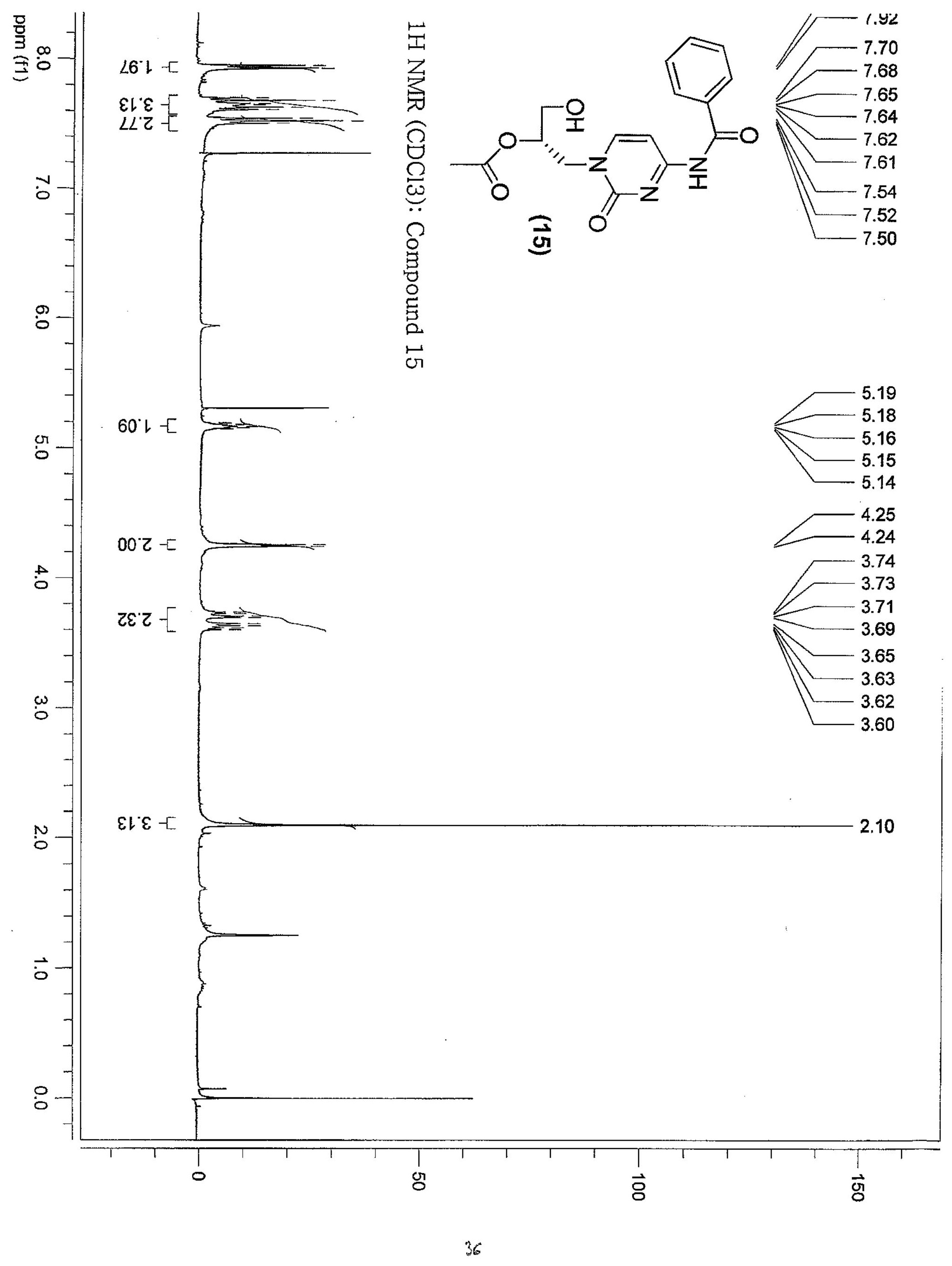



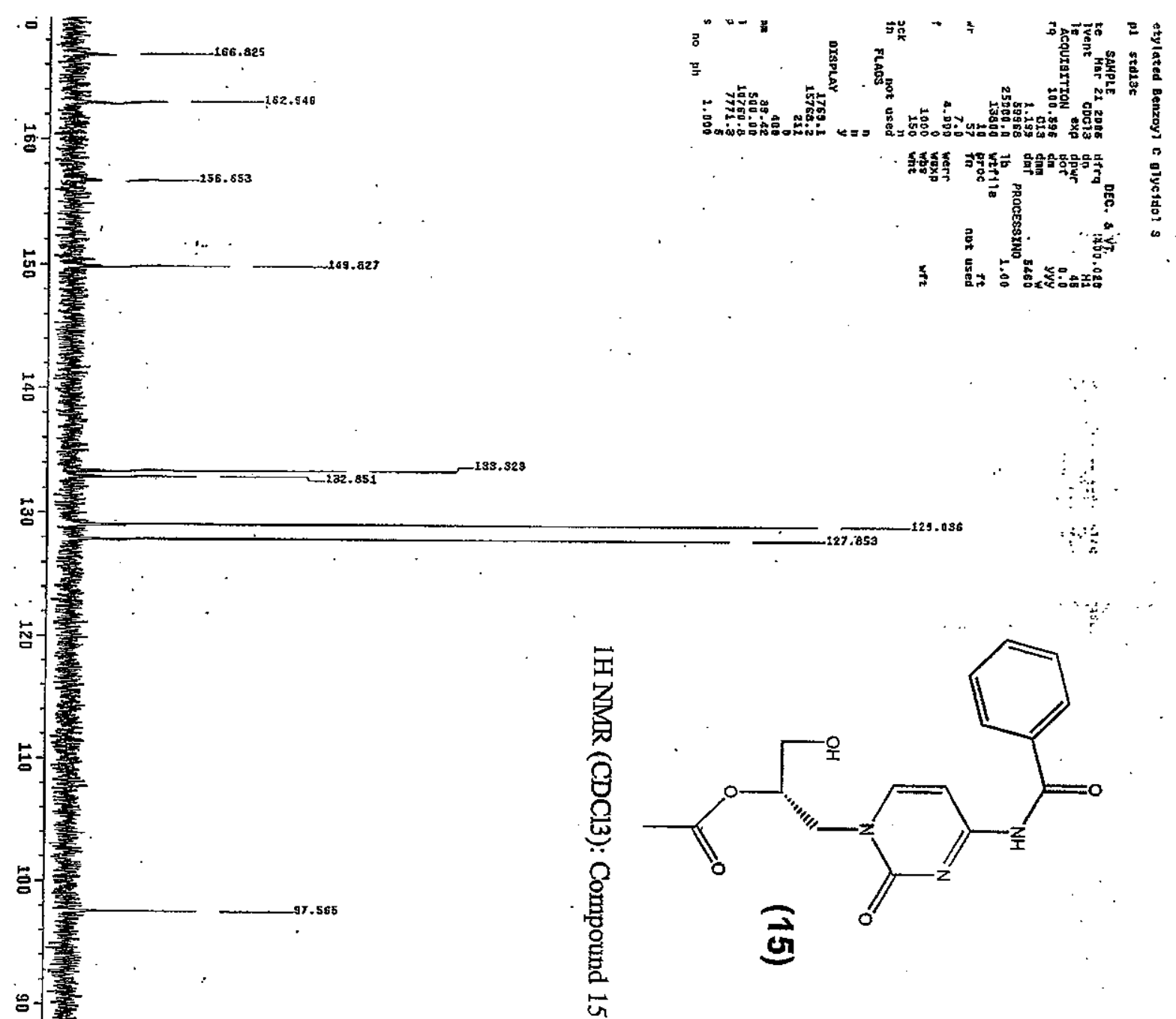

g음

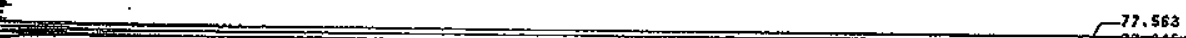




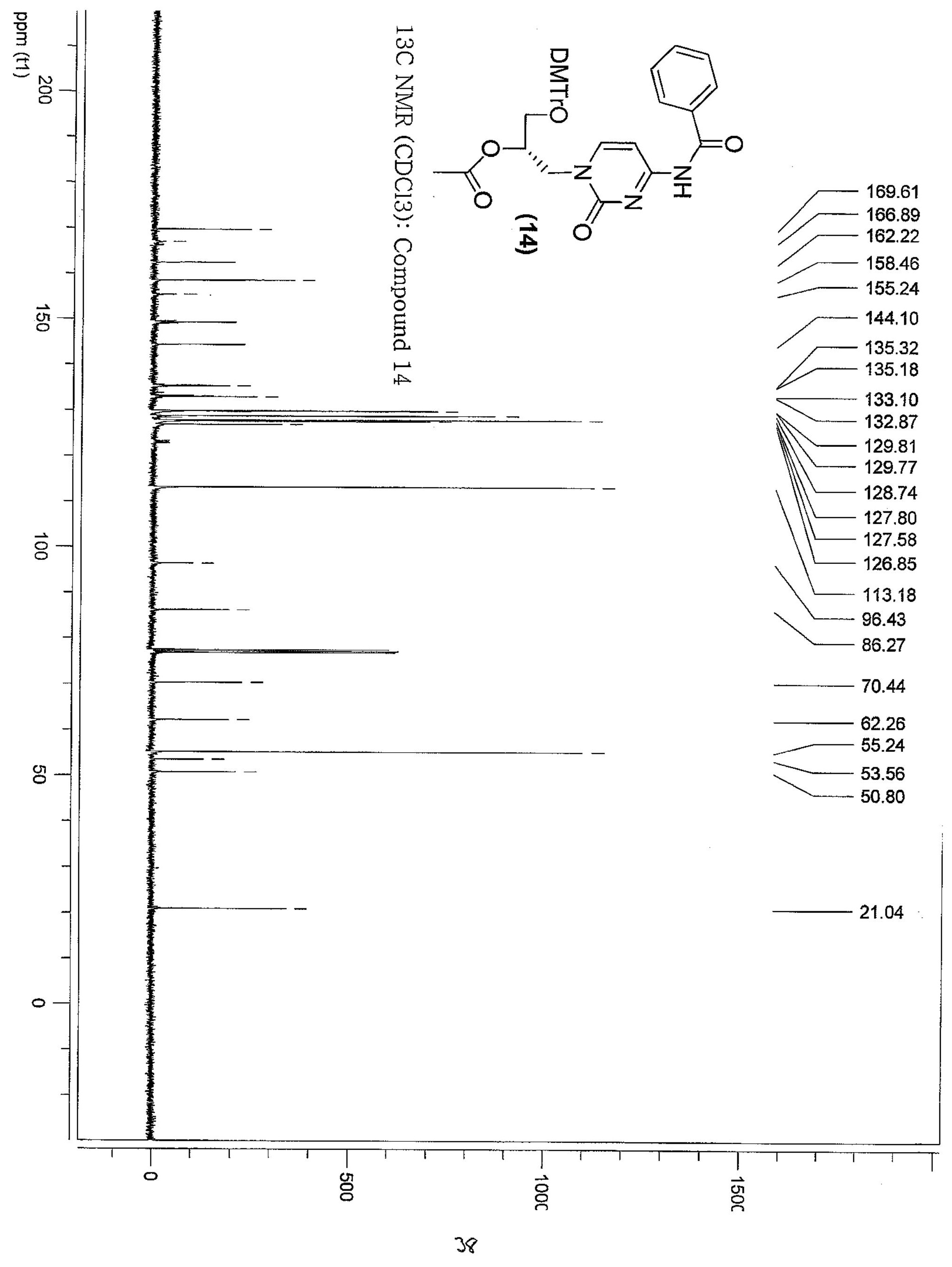




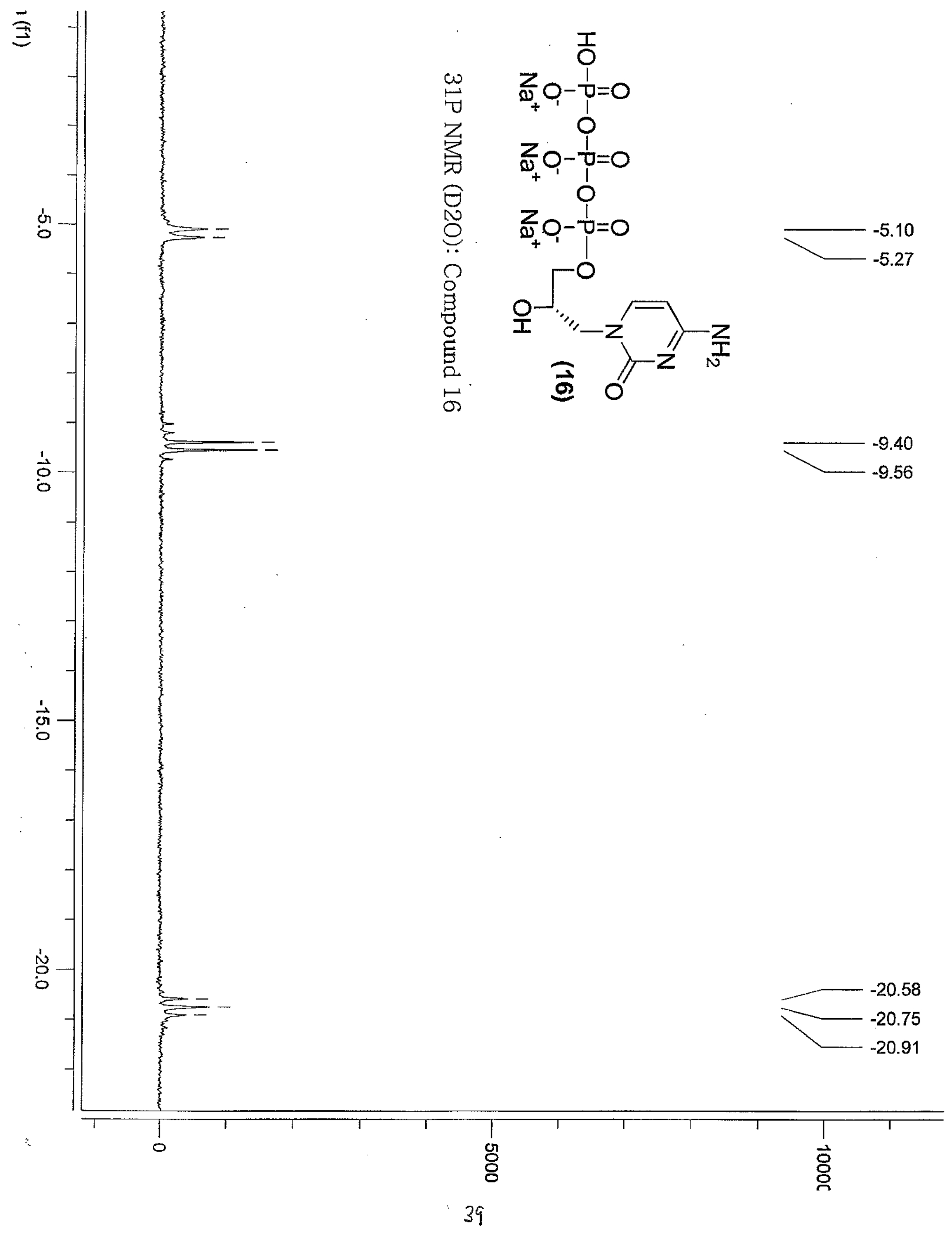




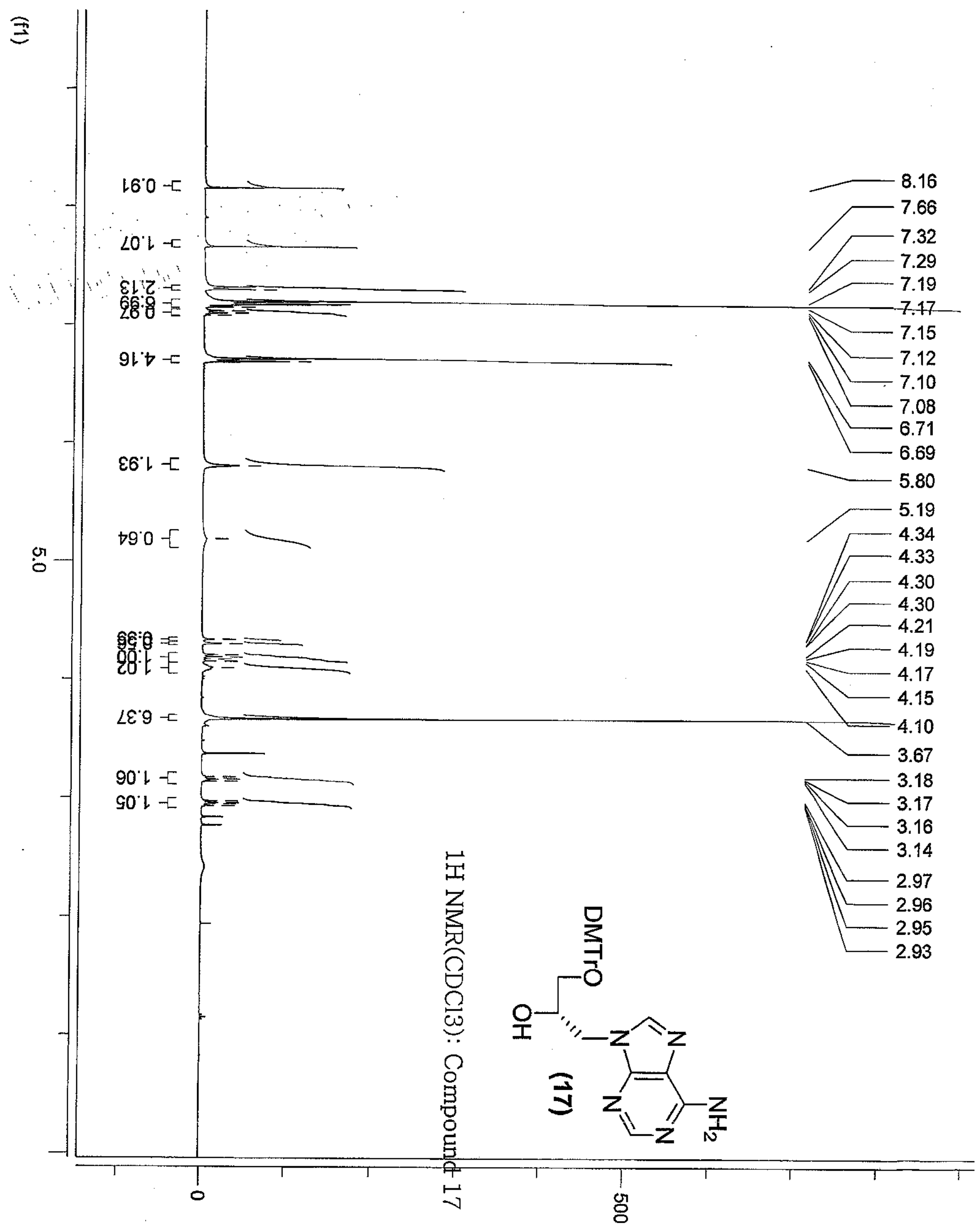




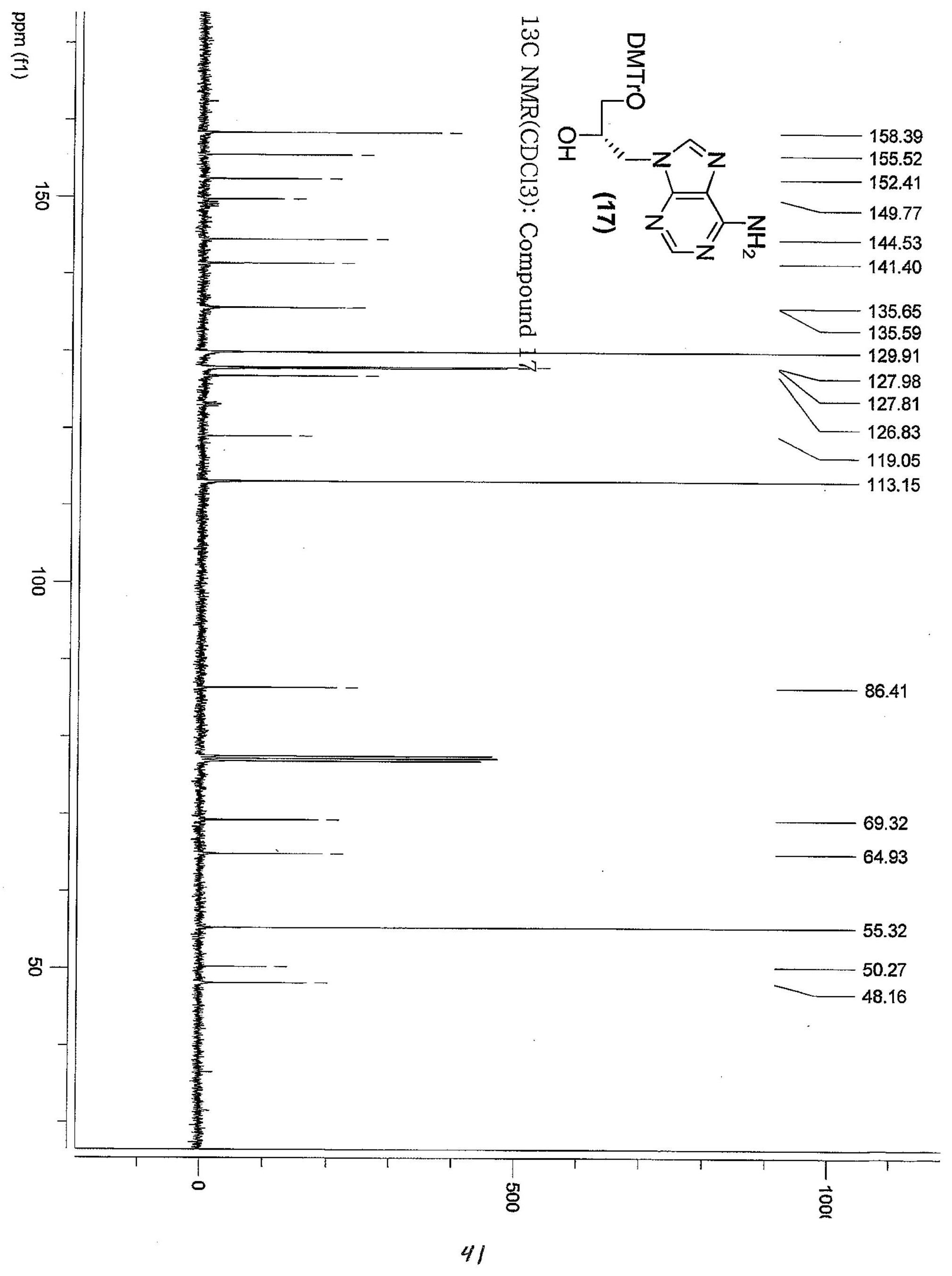




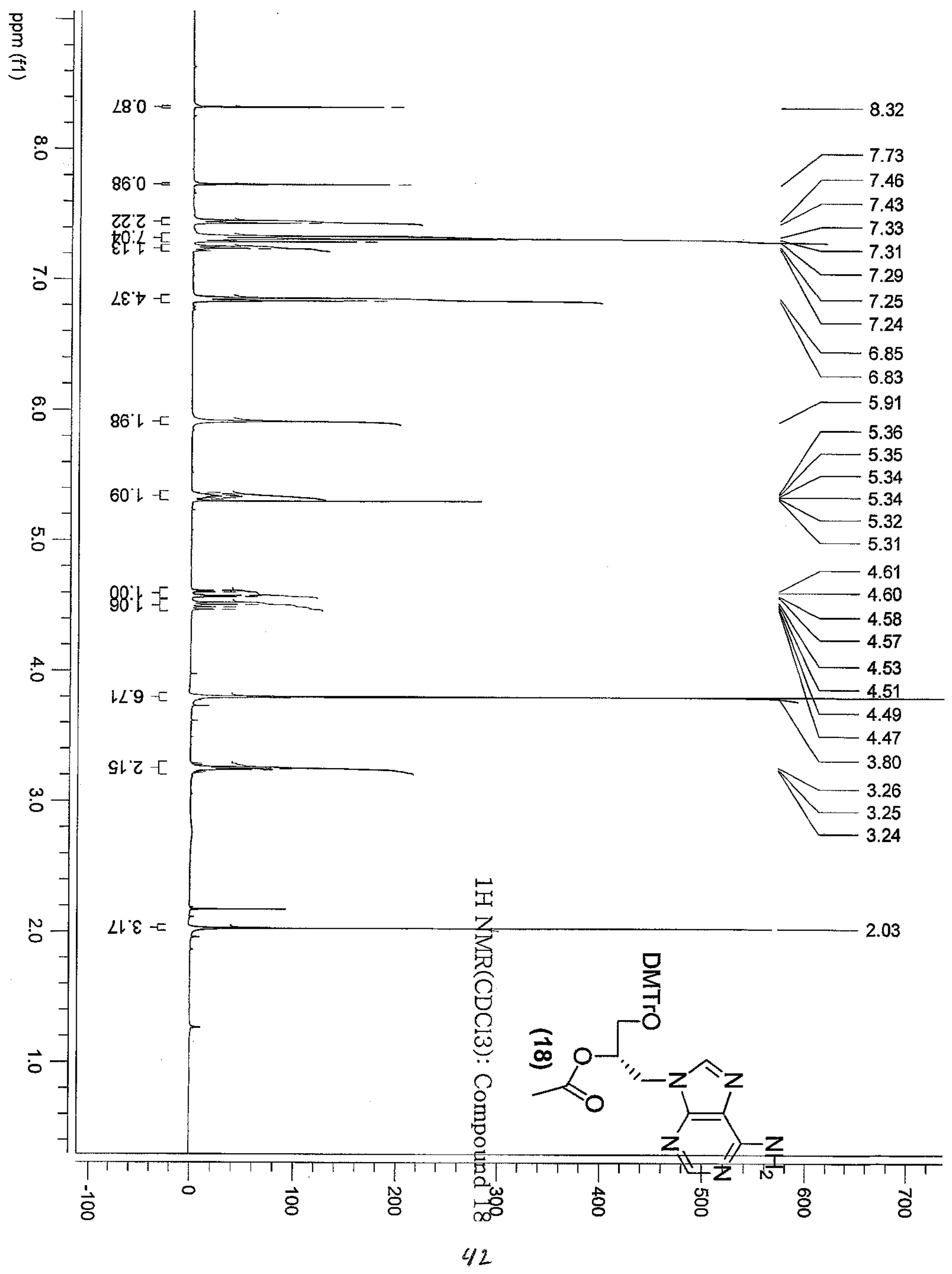




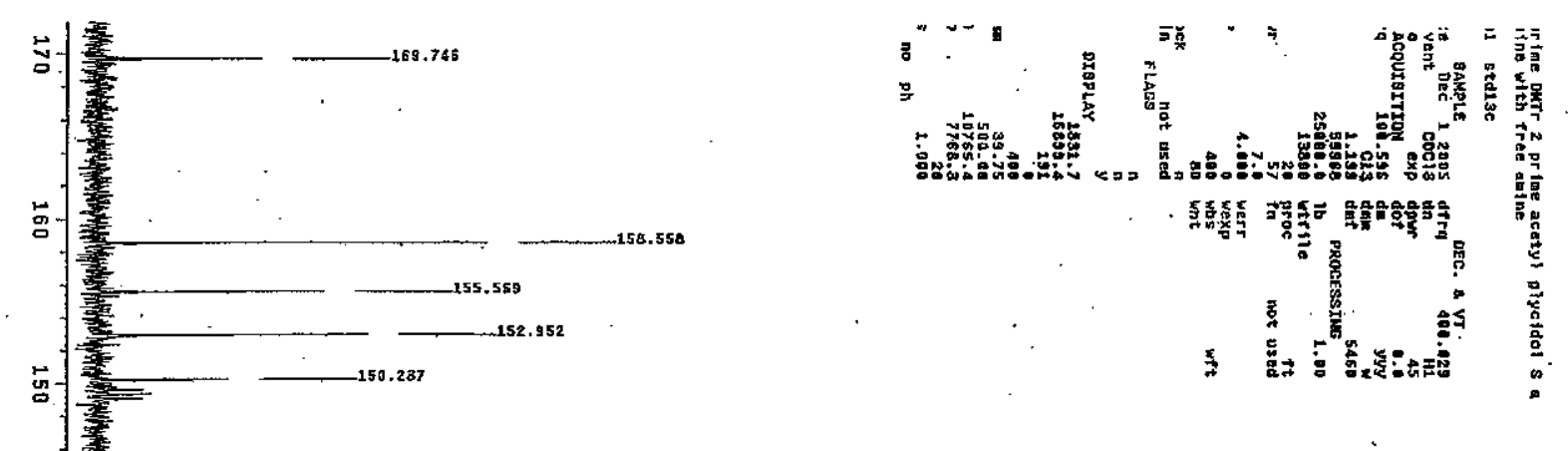

孛

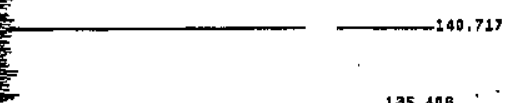

$\underbrace{135.408}_{-135.978}$

㟧-
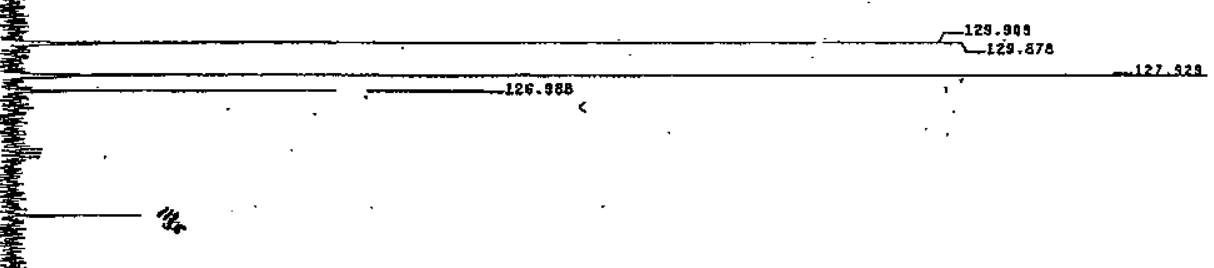

占-

餐

s.

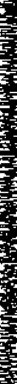

욤

吅
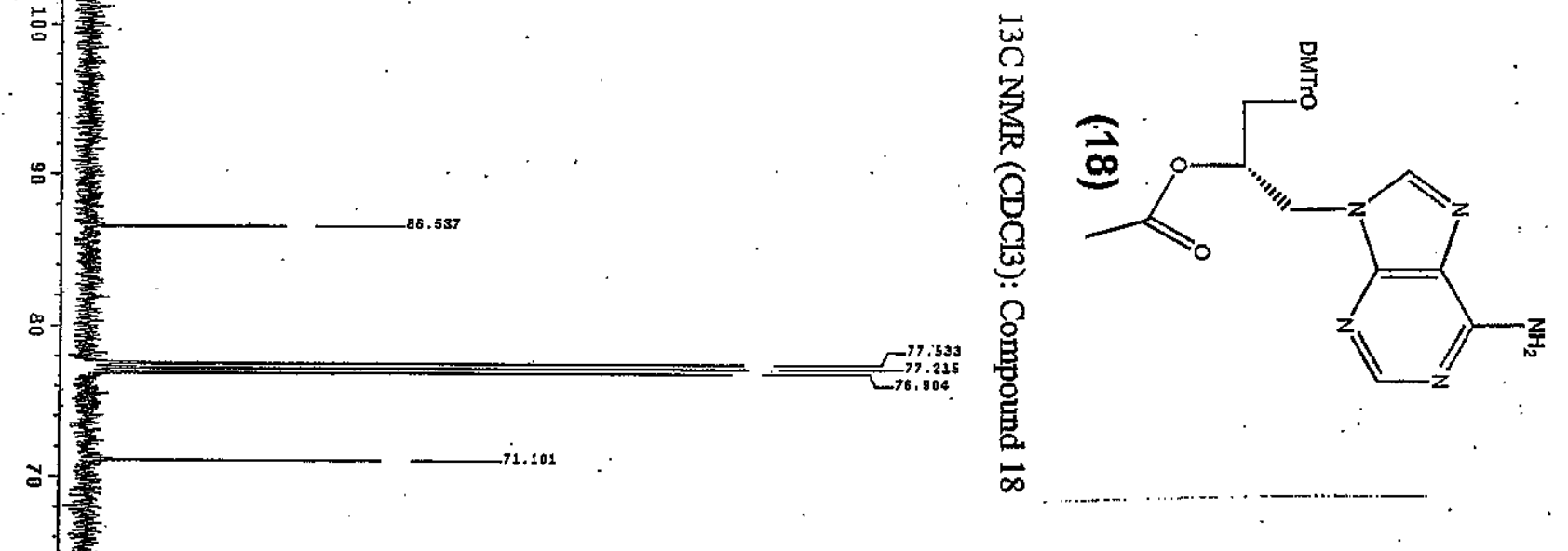

s-
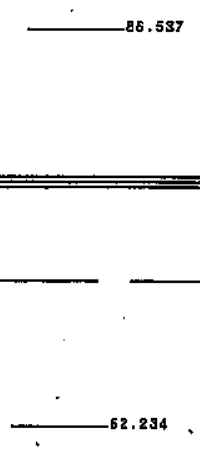

\section{(}




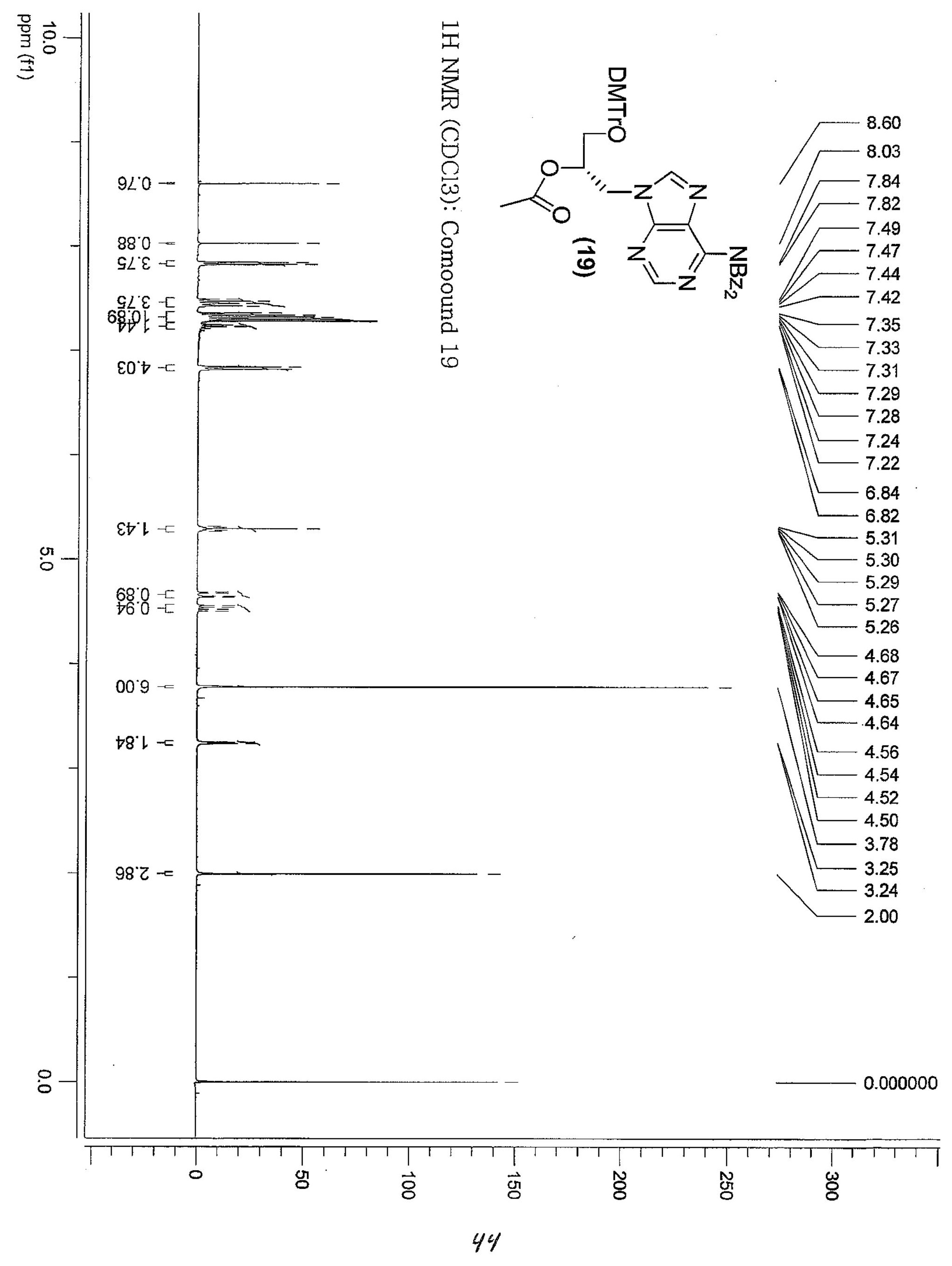




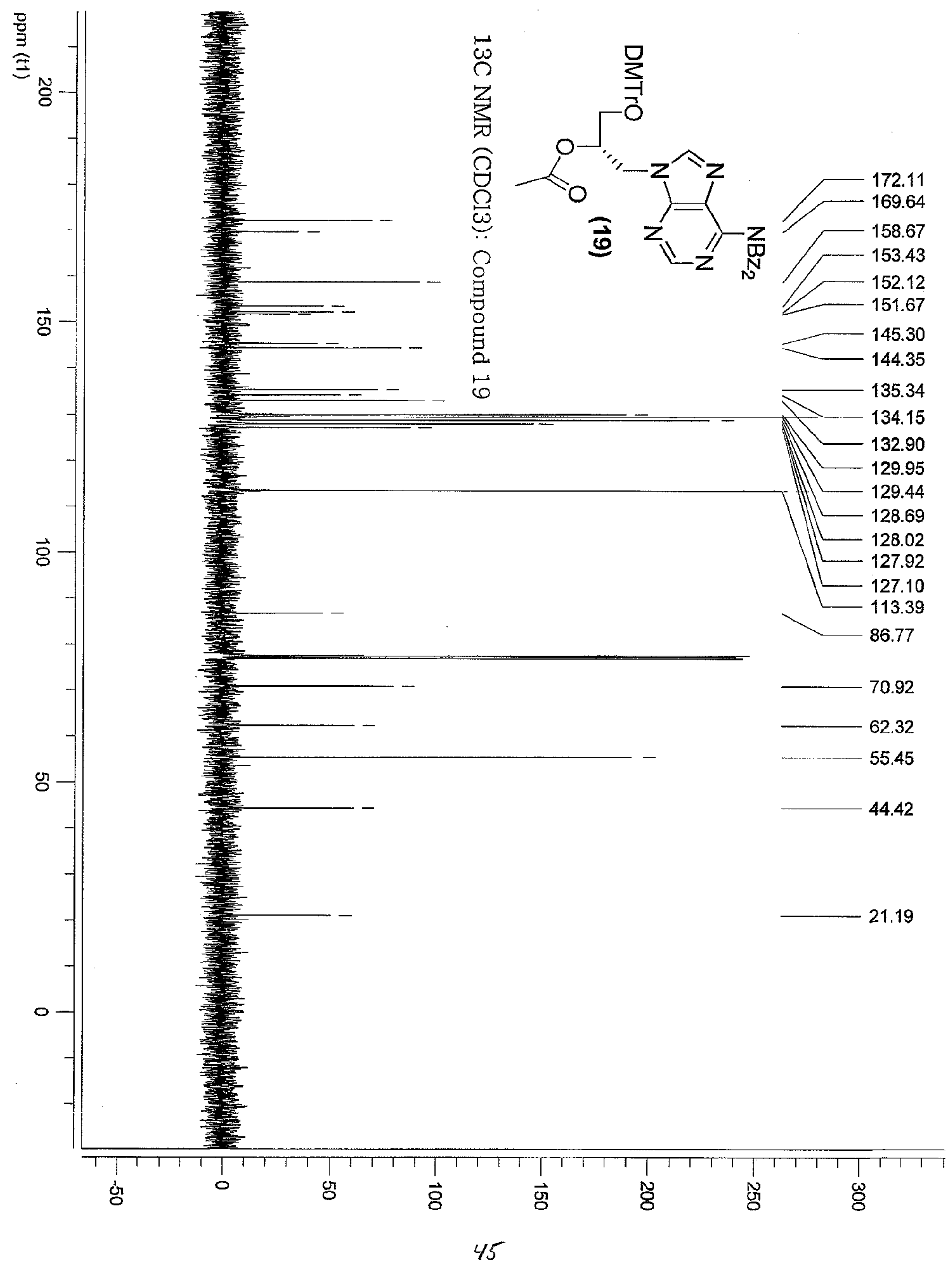




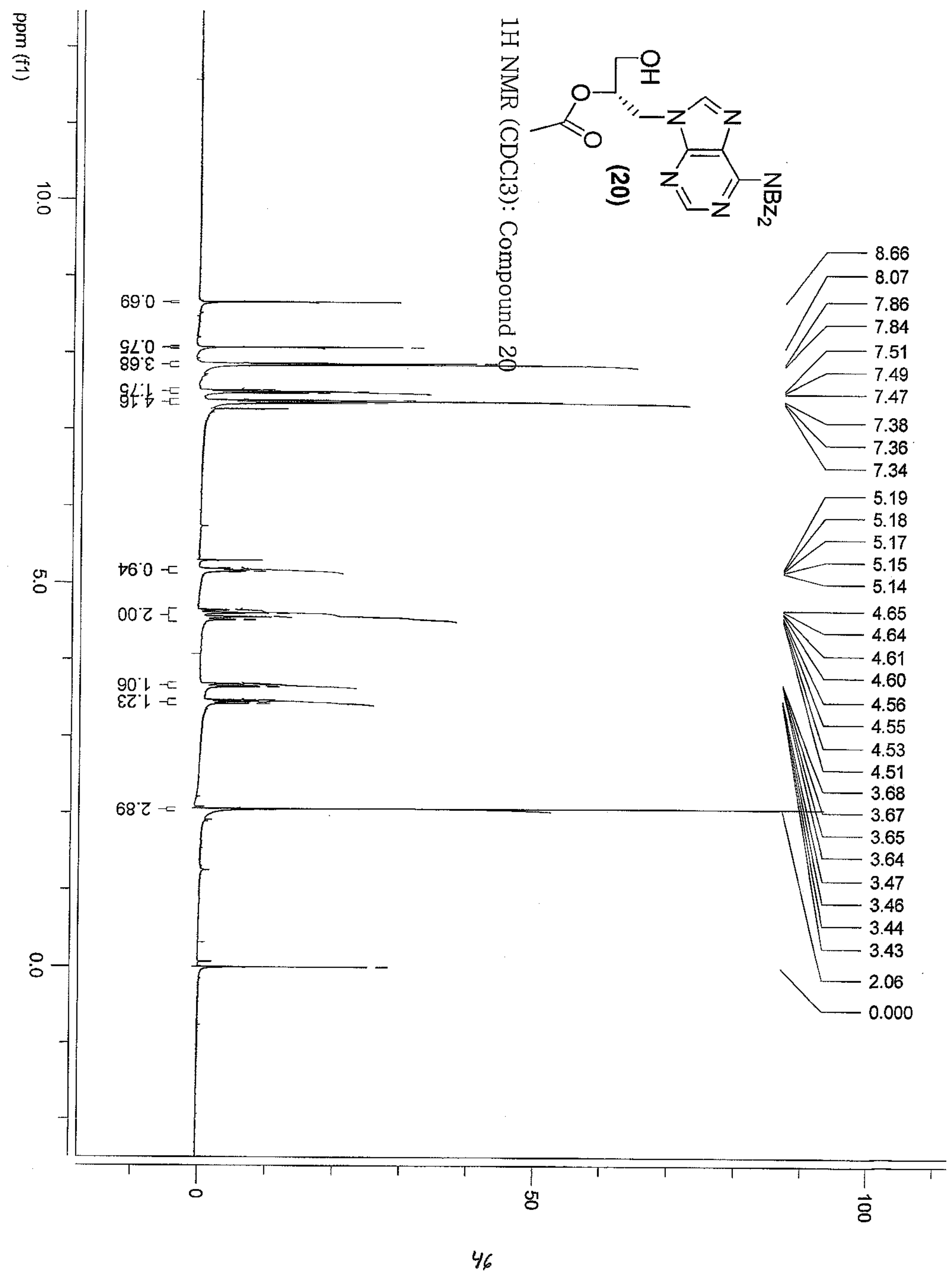



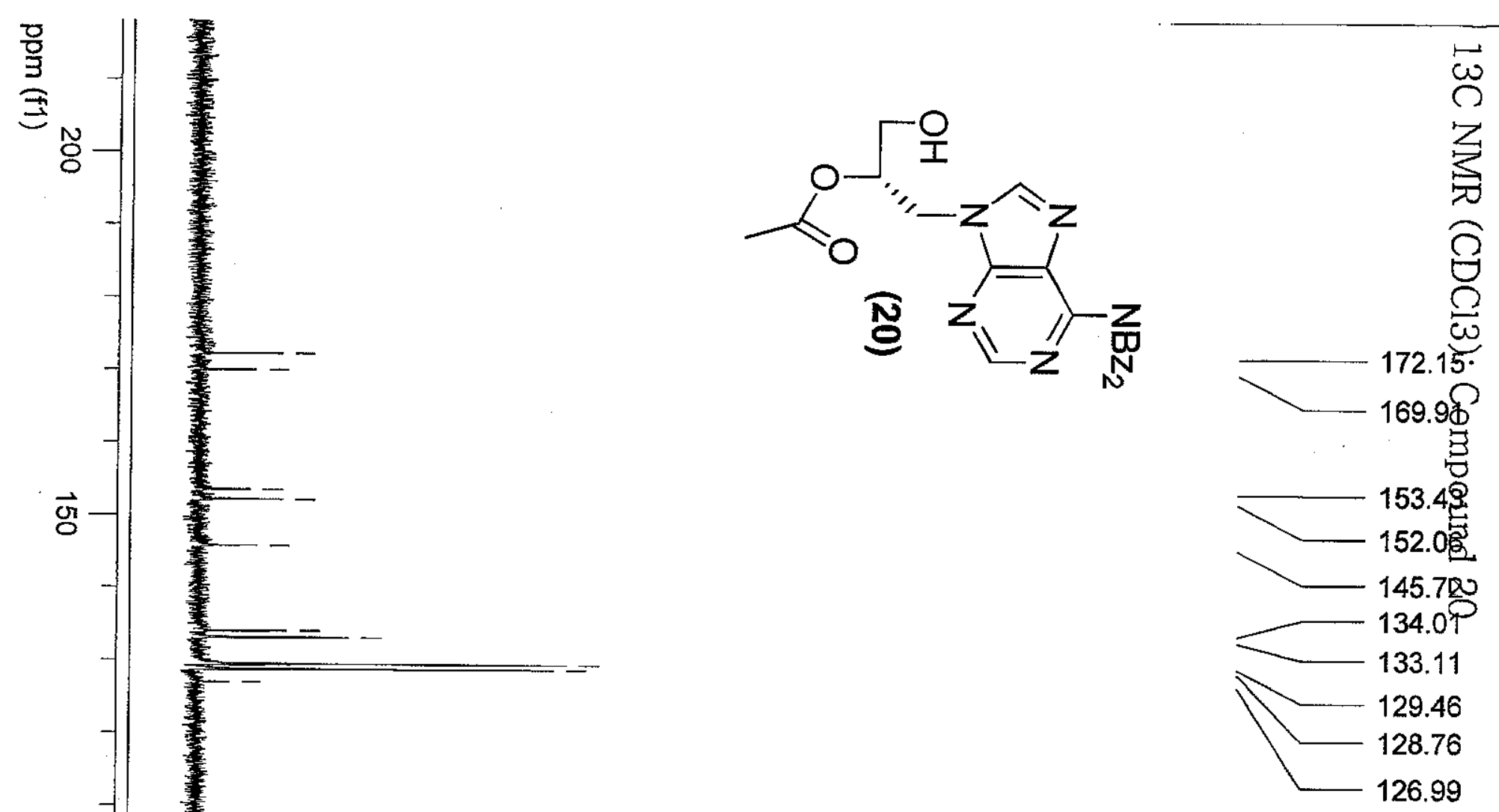

하
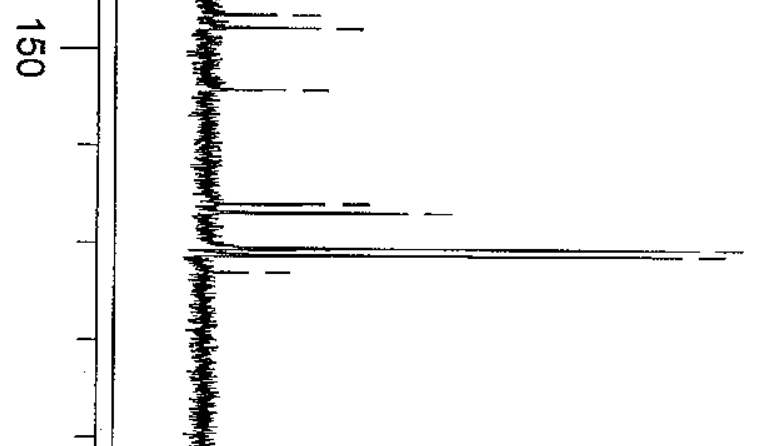

71.86

60.07

43.41

21.16

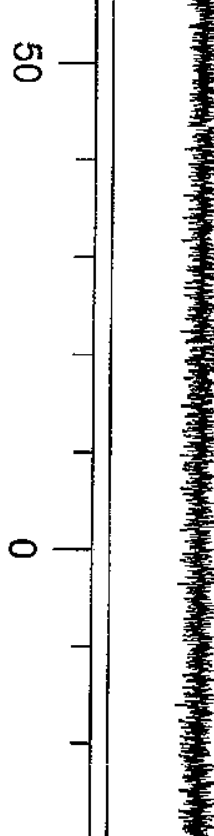

!

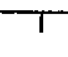

$1+1$ 


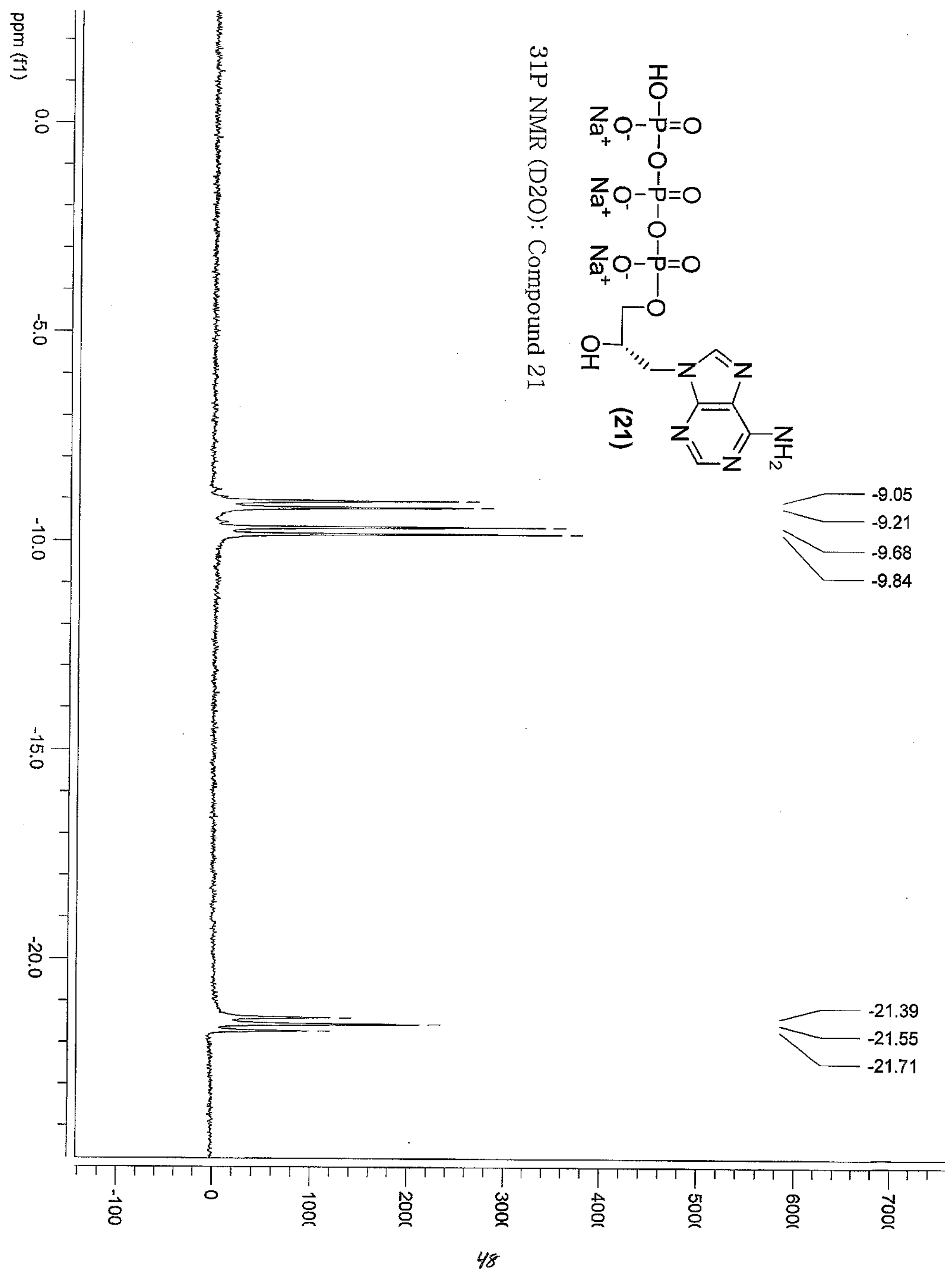

